\title{
Phytoplankton response to deep seawater nutrient addition in the North Pacific Subtropical Gyre
}

\author{
Claire Mahaffey ${ }^{1,2, *}$, Karin M. Björkman ${ }^{1}$, David M. Karl ${ }^{1}$ \\ ${ }^{1}$ Department of Oceanography, SOEST, University of Hawaii, Honolulu, Hawaii 96822, USA \\ ${ }^{2}$ Present address: School of Environmental Sciences, University of Liverpool, Liverpool L69 3GP, UK
}

\begin{abstract}
We examined the phytoplankton response to the addition of nutrient-enriched deep seawater (DSW) and of nitrate only during shipboard experiments performed between July 2004 and May 2007 in the North Pacific Subtropical Gyre (NPSG). Chlorophyll a (chl a), community size structure and composition, carbon fixation (CF) rates, and nutrient concentrations were measured daily for 5 to $7 \mathrm{~d}$ under simulated in situ conditions. Despite the fact that the NPSG is a permanently stratified, oligotrophic biome, there was a seasonal response to the addition of DSW and nitrate. In summertime experiments, chl $a$ and CF rates increased up to 18- and 22-fold, respectively, relative to unamended controls after an incubation period of 5 to $6 \mathrm{~d}$. Nutrients were assimilated to below control concentrations. A shift from a Prochlorococcus-dominated to a Synechococcus- and diatom-dominated community, and an 8- to 12-fold increase in the chl a content of the $>2 \mu \mathrm{m}$ size fraction were observed. Addition of nitrate only increased chl $a$ and CF rates 10- and 7 -fold, respectively. In wintertime experiments, chl $a$ and CF rates increased up to 4 - and 9-fold, respectively, after an incubation period of up to $7 \mathrm{~d}$. Only $50 \%$ of nutrients were assimilated and nitrate alone stimulated a 2 -fold increase in chl $a$ and CF rates. We explore the role of nutrient limitation, community composition, grazing, and light in explaining our observations. Findings from this seasonal and multi-year field experiment demonstrate how little we know about bloom development in the NPSG and highlight the potential risk in extrapolating the response of phytoplankton to natural or artificial fertilization from short-term studies.
\end{abstract}

KEY WORDS: North Pacific Subtropical Gyre $\cdot$ Station ALOHA $\cdot$ Phytoplankton blooms $\cdot$ Deep seawater addition

Resale or republication not permitted without written consent of the publisher

\section{INTRODUCTION}

The balance between the supply of dissolved inorganic nutrients by upward diffusion processes and the downward export flux of particulate matter, derived from primary production, ultimately determines the ocean's role in the global carbon cycle (Eppley \& Peterson 1979). In coastal and subpolar regions, the physical supply of nutrients through tidal or convective mixing maintains a regular or seasonal supply of nutrients and selects for an ecosystem dominated by large $(>2 \mu \mathrm{m})$ phytoplankton and high rates of primary and export production. In contrast, the vertical flux of nutrient-enriched deep seawater into the surface waters of the permanently stratified subtropical gyres is generally low, resulting in an ecosystem dominated by small $(<2 \mu \mathrm{m})$ phytoplankton, such as Prochlorococcus and Synechococcus, and growth is sustained through intense recycling of nutrients, which results in minimal export of organic material out of the euphotic zone (Karl 1999, Karl et al. 2001, Cullen et al. 2002). However, the advent of time-series programs and autonomous sampling platforms has challenged the view that subtropical gyres are 'climax' succession regions or ocean deserts (Karl 1999, Johnson et al. 2010). Instead, studies have shown that short-lived, stochastic events (e.g. eddies, Johnson et al. 2010) as well as long-term cli- 
matic events (e.g. the El Niño Southern Oscillation [ENSO], Karl et al. 2001) have a profound influence on the microbes and biogeochemistry of these subtropical waters. Indeed, data collected from timeseries observations (Karl et al. 1996, Dore et al. 2008, Church et al. 2009), satellite-derived ocean color data (Wilson et al. 2007, Wilson \& Qiu 2008), in situ moorings (Emerson et al. 2002), and cruises of opportunity (Fong et al. 2008) in the North Pacific Subtropical Gyre (NPSG) have reported the fairly regular, if not yet fully understood (White et al. 2007), occurrence of extensive phytoplankton blooms dominated by large phytoplankton which overprint the extant population of Prochlorococcus (Barber \& Hiscock 2006). Sediment trap data from the Hawaii Ocean Time-series (HOT) sampling site, Station ALOHA, in the NPSG shows there are principally 2 bloom-derived export events per year, one in winter supported by nitrate assimilation (Karl et al. 1996) and the other in summer driven by dinitrogen $\left(\mathrm{N}_{2}\right)$ fixation (Karl et al. 1995, Dore et al. 2008, Church et al. 2009). The summertime bloom supports the greater rate of particle export that reaches the seabed (Karl et al. 1996, 2012).

Several mechanisms have been proposed to explain the occurrence of blooms in the NPSG, including both positive (Emerson et al. 2002) and negative (Letelier et al. 2000, Sakamoto et al. 2004, Church et al. 2009) sea surface height anomalies associated with eddies, deepening of the mixed layer in winter (Karl et al. 1995, Bingham \& Lukas 1996), and episodic upwelling or dust deposition events (Calil et al. 2011). Short-lived (weeks) summertime blooms alone may be responsible for up to $20 \%$ of annual new production in the NPSG (Dore et al. 2008), and thus it is vital that we understand not only the mechanisms that drive their development, but the physiological and community response of phytoplankton to the physical or biological supply of nutrients.

Our current knowledge of phytoplankton blooms in subtropical gyres is poor due to their spatial and temporal heterogeneity, despite their critical role in bio-elemental cycling and carbon export (Sarthou et al. 2005, Dore et al. 2008, Decembrini et al. 2009, Karl et al. 2012). In a bloom dominated by diatoms or diatoms containing endosymbiotic $\mathrm{N}_{2}$-fixing cyanobacteria, such as Richelia, the end of the bloom is most likely characterized by aggregation and rapid export of particulate matter (Scharek et al. 1999, Dore et al. 2008, Subramaniam et al. 2008, Karl et al. 2012). In contrast, the traditional view of the fate of organic matter from blooms dominated by small cells (e.g. Synechococcus) or some $\mathrm{N}_{2}$ fixers (e.g. Trichodesmium) is that they do not sink but that instead their organic matter is recycled in the surface ocean, thus benefiting other microbes but not necessarily leading to net carbon sequestration. There is emerging evidence that the relationship between community size structure and export is not that straightforward (Richardson \& Jackson 2007, Boyd et al. 2008, Lomas \& Moran 2011). Nevertheless, understanding the physiological and community dynamics during phototrophic bloom development in important oceanographic biomes is key to unraveling the potential fate of organic carbon.

To further our understanding of bloom development in the NPSG and investigate changes in community size structure, composition and physiology, 10 separate nutrient addition experiments were performed in the NPSG over a $3 \mathrm{yr}$ period. The intent was to supply the surface-dwelling, nutrientdeprived microbial assemblage with nutrientenriched deep seawater (DSW) that contains all the necessary bio-elements for phytoplankton growth. We hypothesized that the addition of DSW would always stimulate a phytoplankton bloom dominated by rapidly growing, opportunistic large phytoplankton. To investigate the role of the proximate limiting nutrient, i.e. nitrate, in controlling phototropic biomass, carbon fixation, and community composition, single nutrient addition experiments were performed in parallel to the DSW incubations on 2 occasions. Using water column measurements and climatology, we explore whether blooms occur irrespective of season or recent water column history.

\section{MATERIALS AND METHODS}

\section{Experimental design and procedures}

Ten DSW addition experiments were performed on cruises to Station ALOHA $\left(22.75^{\circ} \mathrm{N}, 158.00^{\circ} \mathrm{W}\right)$ in the NPSG between July 2004 and May 2007 (Table 1). Sampling techniques and experimental design were similar to those described by McAndrew et al. (2007). Briefly, filtered DSW from $700 \mathrm{~m}$ or filtered seawater from $30 \mathrm{~m}$ was added to pre-cleaned (acid-washed, deionized water-rinsed) 201 polycarbonate carboys which contained unfiltered seawater collected at $30 \mathrm{~m}$. These carboys were then completely filled with $30 \mathrm{~m}$ seawater and represented the treatment $(4.5 \%$ vol:vol DSW addition) and control (0\% vol:vol DSW addition) incubations, respectively. Maximum nutrient concentrations were measured at $700 \mathrm{~m}$ at Sta- 
Table 1. Details on experimental setup; date, duration (h), sea surface temperature (SST), mixed layer depth (MLD), day length, solar power at noon, mean $( \pm 1 \mathrm{SD}$ ) daily light flux for $3 \mathrm{~d}$ (assuming a mixing rate $\leq 1 \mathrm{~d}$ ) from the start of the experiment, and properties measured for control, deep seawater (DSW), and single nutrient (nitrate) addition experiments (186-N 191-N, conducted on HOT cruises 186 and 191, respectively). Parameters measured include nitrate plus nitrite $\left(\mathrm{NO}_{3}+\mathrm{NO}_{2}\right)$, phosphate $\left(\mathrm{PO}_{4}\right)$, silicate $\left(\mathrm{SiO}_{4}\right)$, chlorophyll a $(\mathrm{chl}$ a) and size-fractionated chl a $(\mathrm{SF}-\mathrm{chl}$ a), rates of carbon fixation $(\mathrm{CF})$ and size-fractionated carbon fixation (SF-CF), and community structure by flow cytometry and accessory pigment distribution. SST, MLD, and solar irradiance data from Hawaii Ocean Time-series (HOT) climatology http://hahana.soest.hawaii.edu/hot/). Day length and solar power at noon are from www.sci.fi/ benefon/sol.html

\begin{tabular}{|c|c|c|c|c|c|c|c|c|c|c|c|}
\hline Cruise & $\begin{array}{l}\text { Start D } \\
\text { date }\end{array}$ & $\begin{array}{l}\text { Duration } \\
\text { (h) }\end{array}$ & $\begin{array}{l}\text { SST } \\
\left({ }^{\circ} \mathrm{C}\right)\end{array}$ & $\begin{array}{l}\text { MLD } \\
(\mathrm{m})\end{array}$ & $\begin{array}{c}\text { Day } \\
\text { length } \\
\text { (h:min) }\end{array}$ & $\begin{array}{c}\text { Solar power } \\
\text { at noon } \\
\left(\mathrm{W} \mathrm{m} \mathrm{m}^{-2}\right)\end{array}$ & $\begin{array}{l}\quad \text { Light } \\
\text { flux } \\
\left(\mathrm{E} \mathrm{m}^{-2} \mathrm{~d}^{-1}\right)\end{array}$ & $\begin{array}{c}\mathrm{NO}_{3}+\mathrm{NO}_{2} / \\
\mathrm{PO}_{4} / \mathrm{SiO}_{4} \\
\left(\mu \mathrm{mol} \mathrm{l}{ }^{-1} \text { or }\right. \\
\left.\mathrm{nmol} \mathrm{l}^{-1}\right)\end{array}$ & $\begin{array}{l}\text { Chl a/ } \\
\text { SF-chla } \\
\left(\mu g l^{-1}\right)\end{array}$ & $\begin{array}{c}\mathrm{CF} / \\
\mathrm{SF}-\mathrm{CF} \\
\left(\mu \mathrm{g} \mathrm{Cl}^{-1} \mathrm{~d}^{-1}\right)\end{array}$ & $\begin{array}{l}\text { Community } \\
\text { structure }\end{array}$ \\
\hline 161 & 13 Jul ‘04 & 120 & 26.44 & $63 \pm 4$ & $13: 20$ & 1233 & $52 \pm 2$ & $+/+/+$ & $+/-$ & $+/-$ & - \\
\hline 163 & 27 Sep ‘04 & $4 \quad 132$ & 27.35 & $48 \pm 6$ & $12: 01$ & 1123 & $42 \pm 3$ & $-/+/+$ & $+/-$ & $+/-$ & - \\
\hline 164 & 30 Oct ‘04 & $4 \quad 132$ & 26.01 & $55 \pm 8$ & $11: 23$ & 983 & $23 \pm 17$ & $-/-/+$ & $+/-$ & $+/-$ & - \\
\hline 165 & 27 Nov ‘04 & $4 \quad 96$ & 25.88 & $35 \pm 11$ & $10: 58$ & 875 & $28 \pm 2$ & $-/+/+$ & $+/-$ & $+/-$ & - \\
\hline 167 & 1 Feb ‘05 & 110 & 24.03 & $73 \pm 10$ & $11: 13$ & 940 & $20 \pm 10$ & $-/+/+$ & $+/-$ & $+/-$ & - \\
\hline 174 & 7 Oct ‘05 & 96 & 26.21 & $81 \pm 7$ & $11: 50$ & 1085 & $38 \pm 4$ & $+/+/+$ & $+/+$ & $+/+$ & + \\
\hline 175 & 11 Nov ‘05 & $5 \quad 170$ & 25.27 & $84 \pm 8$ & $11: 11$ & 932 & $36 \pm 1$ & $+/+/+$ & $+/+$ & $+/+$ & + \\
\hline 183 & 12 Jul ‘06 & 144 & 25.31 & $56 \pm 8$ & $13: 20$ & 1233 & $44 \pm 5$ & $+/+/+$ & $+/+$ & $+/+$ & + \\
\hline 186 & 19 Oct ‘06 & $6 \quad 120$ & 26.21 & $50 \pm 7$ & $11: 36$ & 1034 & $32 \pm 6$ & $+/+/+$ & $+/+$ & $+/+$ & + \\
\hline $186-\mathrm{N}$ & 19 Oct ‘06 & $6 \quad 120$ & 26.21 & $50 \pm 7$ & $11: 36$ & 1034 & $32 \pm 6$ & $+/+/+$ & $+/+$ & $+/+$ & Pigments \\
\hline 191 & 3 May ‘07 & $7 \quad 120$ & 24.65 & $55 \pm 8$ & $12: 58$ & 1226 & $47 \pm 2$ & $+/+/+$ & $+/+$ & $+/+$ & + \\
\hline $191-\mathrm{N}$ & 3 May ‘07 & $7 \quad 120$ & 24.65 & $55 \pm 8$ & $12: 58$ & 1226 & $47 \pm 2$ & $+/+/+$ & $+/+$ & $+/+$ & Pigments \\
\hline
\end{tabular}

tion ALOHA (e.g. nitrate + nitrite [mean $\pm 1 \mathrm{SD}]=$ $40.09 \pm 0.71 \mu \mathrm{mol} \mathrm{l}^{-1}, \mathrm{n}=306 ;$ phosphate $=2.94 \pm 0.06$ $\mu \mathrm{mol} \mathrm{l}^{-1}, \mathrm{n}=295$; silicate $=86.09 \pm 4.31 \mu \mathrm{mol} \mathrm{l}^{-1}, \mathrm{n}=$ 279), and therefore using water from $700 \mathrm{~m}$ allowed the smallest volume of seawater to be added to the incubation carboys and minimized dilution of surface phytoplankton. The percentage volume added $(4.5 \%$ vol:vol) was chosen in order to, at the very least, more than double surface phosphate concentrations and to allow comparison with previous DSW addition experiments conducted at Station ALOHA (McAndrew et al. 2007). A treatment and control carboy were prepared for each time point sampled during the experiment (e.g. a $120 \mathrm{~h}$ experiment, sampled daily, would require 6 treatment and 6 control carboys). Temperature, light quantity and spectral quality at $30 \mathrm{~m}$ were simulated in on-deck plastic incubators using surface seawater and blue plastic sheeting (30\% light level, Rohm and Haas \#2069). Carboys were placed in incubators for up to $170 \mathrm{~h}$ (Table 1). In October 2006 and May 2007, single nutrient addition carboys were prepared in parallel to the DSW experiments by adding potassium nitrate (ACS-grade, purity $>99.0 \%$, Sigma Aldrich, 221295) to a set of $20 \mathrm{l}$ carboys to reach a final concentration of $2 \mu \mathrm{mol} \mathrm{l^{-1 }}$, similar to that introduced through the DSW addition. To establish the initial conditions of each experiment (i.e. time $\left.0, T_{0}\right)$, samples for nutrients, phototrophic biomass and carbon fixation were taken from both the control and treatment carboys. Samples for determination of the initial community composition were only taken from the control at $T_{0}$. At each subsequent time point, 1 control and 1 treatment carboy were sacrificed and sampled for a selection of biogeochemical parameters (see Table 1, and below) including (1) nutrients: nitrate, phosphate, and silicate, (2) total chlorophyll a (tchl a) (3) rates of carbon fixation (CF), (4) size-fractionated chl $a$ and CF (SF-chl $a$ and SF-CF, respectively), (5) microbial community composition by flow cytometry (FCM) and (6) diagnostic phytoplankton pigments using high-performance liquid chromatography (HPLC). To investigate the impact of the addition of nutrient-enriched DSW or nitrate only, con-

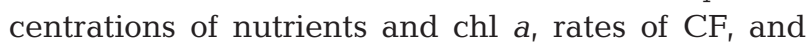
microbial community composition in treatment incubations were normalized to the control by subtracting the control values for each parameter measured from the values in the treatment incubation. The absolute change in measurements (expressed as $\Delta$ in Table 2), as well as change relative to starting values (expressed as 'fold' change) between the start $\left(T_{0}\right)$ and final time point $\left(T_{\mathrm{f}}\right)$ of the control and treatment incubations, or in some cases, the time of maximum concentration in chl $a$ or CF rate ( $\left.T_{\text {peak }}\right)$ were determined. Due to the sampling regime chosen and incubation logistics involved in these experiments, replication of the control and treatment carboys was not performed, but instead, the experiment was sampled at 
higher temporal resolution. Hence, the data at $T_{0}$ and $T_{\mathrm{f}}$ for each experiment were grouped to create 10 replicates (i.e. 10 data points for control at $T_{0}, 10$ data points for control at $T_{\mathrm{f}}, 10$ data points representing $T_{\mathrm{f}}$ - $T_{0}$ for control incubations, repeated for treatment incubations), and then separated into 2 groups: fallwinter experiments (September to February, herein referred to as winter) and spring-summer experiments (May to July, herein referred to as summer). To determine if changes in parameters between control and treatment incubations, and wintertime and summertime experiments were statistically significant, ANOVA and Tukey's honestly significant difference (HSD) tests were performed using data from $T_{0}, T_{\mathrm{f}}$ and $T_{\text {peak }}$. To account for the variable duration of the experiments (96 to $170 \mathrm{~h}$ ), we examined the change in parameters between $T_{0}$ and time points at $96 \mathrm{~h}$ $\left(T_{96 \mathrm{~h}}\right)$ and $120 \mathrm{~h}\left(T_{120 \mathrm{~h}}\right)$, as well as $T_{\text {peak }}$ (which sometimes coincided with $T_{96 \mathrm{~h}}$ or $T_{120 \mathrm{~h}}$ ) and $T_{\mathrm{f}}$. In all cases, comparison of values at $T_{96 \mathrm{~h}}$ and $T_{120 \mathrm{~h}}$ made no difference to the overall conclusions relative to those observed at $T_{\text {peak }}$ and $T_{\text {final, }}$, and therefore we report results between $T_{0}$ and $T_{\text {peak }}$ and $T_{\mathrm{f}}$ only.

\section{Nutrients and chlorophyll a}

Seawater samples for analysis of nitrate, phosphate, and silicate were collected into acid-washed, deionized water-rinsed polyethylene bottles and stored frozen at $-20^{\circ} \mathrm{C}$ until analyzed. Nitrate and silicate concentrations $\left(\mu \mathrm{mol} \mathrm{l}^{-1}\right.$ ) were determined using a segmented flow Bran and Luebbe (AA3) continuous flow nutrient analyzer using standard colorimetric techniques (Armstrong et al. 1967). When nitrate concentrations were $<0.5 \mu \mathrm{mol}^{-1}$, samples were analysed using a chemiluminescence technique with a detection limit and precision of 1 and $\pm 0.5 \mathrm{nmol} \mathrm{l}^{-1}$, respectively (Garside 1982, Dore \& Karl 1996). Silicate concentrations $<1 \mu \mathrm{mol} \mathrm{l}^{-1}$ were determined manually using standard colorimetric techniques (Strickland \& Parson 1972) with a detection limit and precision of 100 and $\pm 20 \mathrm{nmol} \mathrm{l}^{-1}$, respectively. Phosphate analyses were performed using the MAGIC technique (Murphy \& Riley 1962, Karl \& Tien 1992), with a detection limit and precision of 3 and $\pm 1 \mathrm{nmol} \mathrm{l}^{-1}$, respectively. Chl a concentrations were determined by filtering between 0.1 and $1 \mathrm{l}$ through a GF/F or $0.2 \mu \mathrm{m}, 2 \mu \mathrm{m}$, and $10 \mu \mathrm{m}$ polycarbonate filter for size-fractionated chl a (see Table 1). Chl a was extracted from the filter by immersing it into $100 \%$ acetone at $-20^{\circ} \mathrm{C}$ in the dark for a minimum of $1 \mathrm{wk}$ (Welschmeyer 1994) and analysis was performed using a TD700 fluorometer (Turner Designs) or a 10-AU fluorometer (Turner Designs). Chl a concentrations are expressed as tchl a (i.e. sum of all size fractions or chlorophyll captured on a GF/F) and size fractions of $0.2-2 \mu \mathrm{m}, 2-10$ $\mu \mathrm{m}$, and $>10 \mu \mathrm{m}$. Whole community and size-fractionated net algal growth rates $\left(\mu, \mathrm{d}^{-1}\right)$ were calculated using chl a concentrations at the $T_{0}$ and $T_{\mathrm{f}}$ (or $T_{\text {peak }}$ ) of the experiments (Fogg \& Thake 1987).

\section{Carbon fixation}

Triplicate samples (except October 2005) were collected from each incubation carboy into acid-cleaned polycarbonate $500 \mathrm{ml}$ bottles for determination of the net inorganic ${ }^{14} \mathrm{C}$-uptake rate, reported as the rate of carbon fixation $\left(\mathrm{CF}_{1} \mu \mathrm{g} \mathrm{C} \mathrm{l}^{-1} \mathrm{~d}^{-1}\right)$. Seawater samples were spiked with ${ }^{14} \mathrm{C}$-bicarbonate to achieve a final activity of approximately $100 \mu \mathrm{Ci}^{-1}$ (or $3.7 \mathrm{MBq}^{-1}$, MP Biomedicals \#17441H) and incubated in an ondeck incubator from dawn to dusk. At the end of the daylight period, seawater samples were size fractionated through $0.2 \mu \mathrm{m}, 2 \mu \mathrm{m}$, and $10 \mu \mathrm{m}$ polycarbonate membrane filters (see Table 1). Filters were placed in borosilicate glass scintillation vials, acidified $(1 \mathrm{ml}$, $2 \mathrm{~N} \mathrm{HCl}$ ) and vented for $24 \mathrm{~h}$ prior to the addition of scintillation cocktail (Ultima Gold, Packard) and subsequent counting in a Perkin Elmer 2600 LSC. Subsamples $(0.25 \mathrm{ml})$ for total ${ }^{14} \mathrm{C}$-radioactivity were collected from each incubation bottle and fixed with $0.5 \mathrm{ml}$ of $\beta$-phenethylamine (Sigma \#P2641). CF rates are expressed as total CF (i.e. sum of all size fractions) and size fractions of $0.2-2 \mu \mathrm{m}, 2-10 \mu \mathrm{m}$, and $>10 \mu \mathrm{m}$.

\section{Community composition}

To investigate community composition, samples were taken for flow cytometry and accessory pigment analyses. For flow cytometry, $2 \mathrm{ml}$ of seawater from each carboy was preserved with paraformaldehyde $(0.2 \%$ final concentration), flash frozen and stored at $-80^{\circ} \mathrm{C}$ until analyzed using a Cytopeia InFlux Mariner flow cytometer equipped with a Sapphire laser (150 mW, $488 \mathrm{~nm}$ ). Unstained samples were used to obtain chl $a$ and phycoerythrin autofluorescent cell counts. Stained samples, using SYBR (Invitrogen), were used to obtain total cell counts. Fluorescent beads (Fluoresbrite $1 \mu \mathrm{m}$, Polysciences) were added to all samples as a size and standardization marker. The FlowJo (Tree Star) software was 
used to enumerate the functional groups: Prochlorococcus (PRO), Synechococcus (SYN), non-pigmented (lacking chl a) bacteria (N-PB), and picoeukaryotic (PEUK) cells, based on their respective fluorescence and size (forward scatter) characteristics. We acknowledge that the N-PB group may have diverse modes of metabolism that cannot be deduced from the FCM cytograms, and we herein refer to this group as non-pigmented bacteria (N-PB) rather than heterotrophic bacteria. Note that the PRO population in the SYBR-stained samples could not be uniquely separated from other stained cells in a similar size range; hence, the N-PB cell numbers are derived from the difference between SYBR-stained cells and PRO cell counts. Also, the flow cytometer was optimized for the analysis of the more abundant PRO and N-PB cells, not for the less abundant SYN and PEUK cells. For pigment analysis, 1 to $4 \mathrm{l}$ of seawater from each carboy was filtered through GF/F filters, and filters were placed into cryovials, purged with nitrogen gas, and stored at $-80^{\circ} \mathrm{C}$ for analysis of chl a and accessory pigment content. Analysis was performed using a Varian 9012 HPLC system according to methods outlined by Wright et al. (1991). In this study, we used the contribution of fucoxanthin relative to tchl $a$ as an indicator for diatoms (Claustre 1994).

\section{RESULTS}

\section{Initial conditions}

Station ALOHA is a permanently stratified, oligotrophic, deep-ocean site sampled by the HOT program. Sea surface temperature $\left(\mathrm{SST}^{\circ}{ }^{\circ} \mathrm{C}\right)$ and mixed layer depth (MLD, m) vary seasonally (Fig. 1a,b, respectively). During cruises sampled for incubation experiments, SST and MLD ranged from 24.03 to $27.35^{\circ} \mathrm{C}$ and 35 to $84 \mathrm{~m}$, respectively (Table 1 ) and were not significantly different from the $>20$ yr climatology at Station ALOHA (Fig. 1a,b). Day length and solar power were minimal during the November 2004 experiment (10 h $58 \mathrm{~min}$ and $875 \mathrm{~W} \mathrm{~m}^{-2}$, respectively) and maximal during the July 2004 and 2006 experiments $\left(13 \mathrm{~h} 20 \mathrm{~min}\right.$ and $1233 \mathrm{~W} \mathrm{~m}^{-2}$, respectively, Table 1). Mean ( $\pm 1 \mathrm{SD})$ summertime day length $(13 \mathrm{~h}$ $13 \mathrm{~min} \pm 13 \mathrm{~min}, \mathrm{n}=3)$ and solar power $(1231 \pm 4 \mathrm{~W}$ $\mathrm{m}^{-2}, \mathrm{n}=3$ ) were significantly longer and higher than mean wintertime day length (11 h $27 \mathrm{~min} \pm 23 \mathrm{~min}, \mathrm{n}$ = 7) and solar power $\left(996 \pm 89 \mathrm{~W} \mathrm{~m}^{-2}, \mathrm{n}=7, \mathrm{p}<0.05\right.$, Table 1). The $3 \mathrm{~d}$ mean $( \pm \mathrm{SD})$ in light flux in the mixed layer varied from a maximum of $52 \pm 2 \mathrm{E} \mathrm{m}^{-2}$ $\mathrm{d}^{-1}$ in July 2004 to a minimum of $20 \pm 10 \mathrm{E} \mathrm{m}^{-2} \mathrm{~d}^{-1}$ in
February 2005 (Table 1). The mean wintertime light flux $\left(31 \pm 8 \mathrm{E} \mathrm{m}^{-2} \mathrm{~d}^{-1}\right)$ was significantly lower $(\sim 65 \%)$ than mean summertime light flux $\left(48 \pm 4 \mathrm{E} \mathrm{m}^{-2} \mathrm{~d}^{-1}\right)$ during the experiments and was more variable
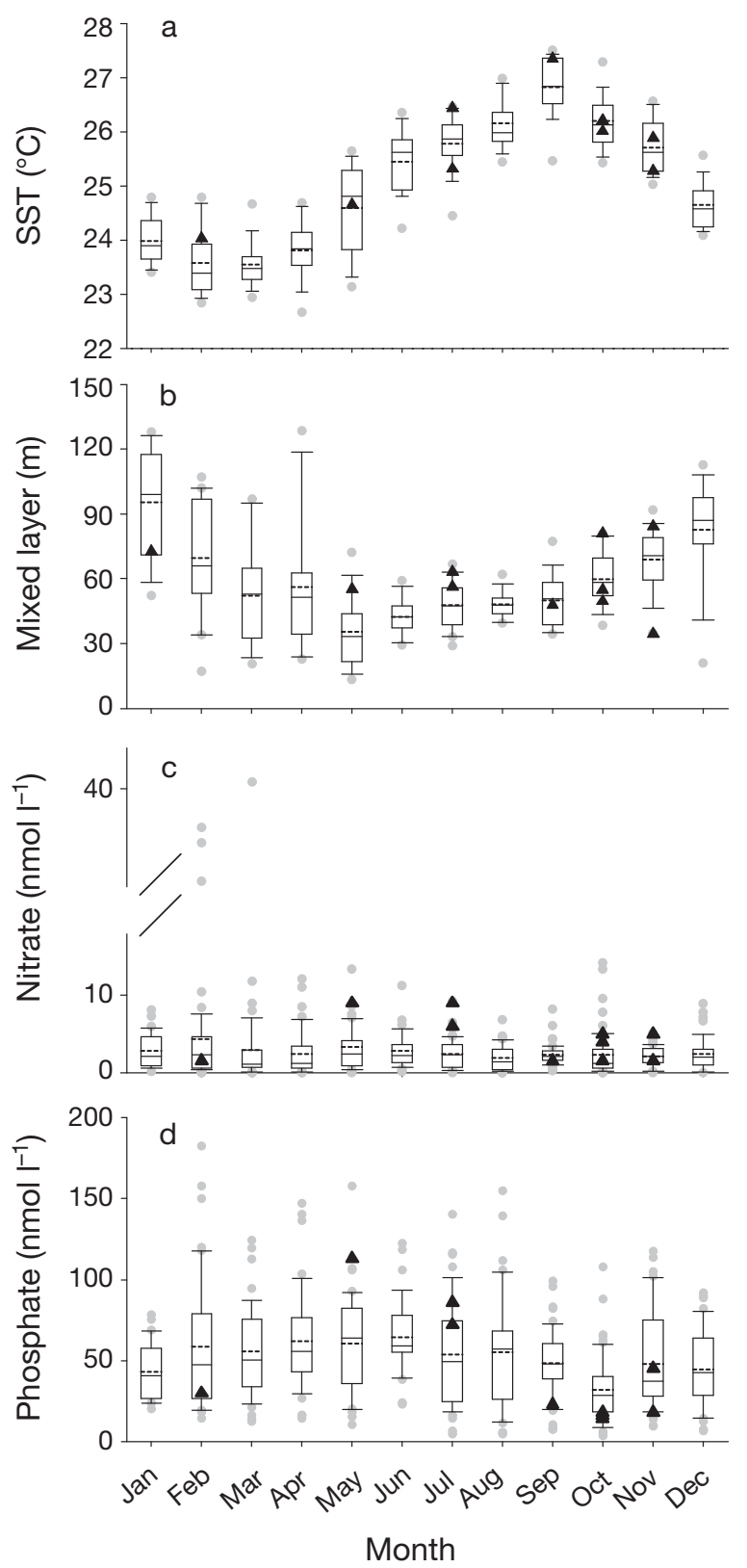

Fig. 1. Seasonal climatology in (a) sea surface temperature (SST), (b) mixed layer depth, the concentration of (c) nitrate and (d) phosphate in the upper $35 \mathrm{~m}$ of the water column at Station ALOHA during 1989-2009. Upper and lower boundaries of the box represents the 25 th and 75 th percentile. Black and dashed lines within the box represent the median and mean, respectively. Whiskers indicate the 10th and 90th percentile, and grey circles represent outliers. Note that values from the 10 experiments are marked with triangles. Mixed layer depth was identified as the depth where there is a density offset of $0.125 \mathrm{~kg} \mathrm{~m}^{-3}$ from the surface $(<5 \mathrm{~m})$ water 
Table 2. Mean $\pm 1 \mathrm{SD}$ of initial properties at time $0\left(T_{0}\right)$ and change in properties at the end of the experiment $\left(\Delta T_{\mathrm{f}}\right)$ in control and treatment incubations (4.5\% vol:vol deep seawater [DSW] and nitrate only [N only]). Properties include nitrate, phosphate, and silicate. Negative values signify a decrease in a property. nd: not determined

\begin{tabular}{|c|c|c|c|c|c|c|c|c|}
\hline Cruise & $\begin{array}{l}\text { Date } \\
/ T_{\mathrm{f}}(\mathrm{h})\end{array}$ & Carboy & $\begin{array}{l}\text { Nitrate } T_{0} \\
\left(\mu \mathrm{mol} \mathrm{l}^{-1}\right)\end{array}$ & $\begin{array}{c}\Delta \text { Nitrate } T_{\mathrm{f}} \\
\left(\mu \mathrm{mol} \mathrm{l^{-1 } )}\right.\end{array}$ & $\begin{array}{l}\text { Phosphate } T_{0} \\
\left(\mu \mathrm{mol} \mathrm{l}^{-1}\right)\end{array}$ & $\begin{array}{c}\Delta \text { Phosphate } T_{\mathrm{f}} \\
\left(\mu \mathrm{mol} \mathrm{l}^{-1}\right)\end{array}$ & $\begin{array}{l}\text { Silicate } T_{0} \\
\left(\mu \mathrm{mol} \mathrm{l}{ }^{-1}\right)\end{array}$ & $\begin{array}{c}\Delta \text { Silicate } T_{\mathrm{f}} \\
\left(\mu \mathrm{mol} \mathrm{l^{-1 }}\right)\end{array}$ \\
\hline 161 & $\begin{array}{r}\text { Jul ‘04 } \\
\text { /120 }\end{array}$ & $\begin{array}{r}\text { Control } \\
\text { DSW }\end{array}$ & $\begin{array}{c}0.009 \\
2.24 \pm 0.07\end{array}$ & $\begin{array}{l}-0.005 \\
-2.19\end{array}$ & $\begin{array}{l}0.086 \pm 0.009 \\
0.257 \pm 0.009\end{array}$ & $\begin{array}{l}-0.048 \pm 0.024 \\
-0.247 \pm 0.010\end{array}$ & $\begin{array}{l}0.82 \pm 0.01 \\
5.41 \pm 0.25\end{array}$ & $\begin{array}{r}0.03 \pm 0.12 \\
-1.20 \pm 0.25\end{array}$ \\
\hline 163 & $\begin{array}{r}\text { Sep `04 } \\
\text { /132 }\end{array}$ & $\begin{array}{r}\text { Control } \\
\text { DSW }\end{array}$ & $\begin{array}{c}<0.002 \\
\text { nd }\end{array}$ & $\begin{array}{l}\text { nd } \\
\text { nd }\end{array}$ & $\begin{array}{l}0.023 \pm 0.000 \\
0.151 \pm 0.002\end{array}$ & $\begin{array}{r}0.000 \pm 0.009 \\
-0.073 \pm 0.005\end{array}$ & $\begin{array}{l}0.81 \pm 0.11 \\
4.55 \pm 0.48\end{array}$ & $\begin{array}{l}-0.02 \pm 0.05 \\
-0.01 \pm 0.35\end{array}$ \\
\hline 164 & $\begin{array}{r}\text { Oct '04 } \\
\quad / 132\end{array}$ & $\begin{array}{r}\text { Control } \\
\text { DSW }\end{array}$ & $\begin{array}{c}<0.002 \\
\text { nd }\end{array}$ & $\begin{array}{l}\text { nd } \\
\text { nd }\end{array}$ & $\begin{array}{l}0.014 \pm 0.000 \\
0.146 \pm 0.005\end{array}$ & $\begin{array}{l}\text { nd } \\
\text { nd }\end{array}$ & $\begin{array}{l}0.64 \pm 0.11 \\
5.24 \pm 0.11\end{array}$ & $\begin{array}{l}0.45 \pm 0.04 \\
0.60 \pm 0.08\end{array}$ \\
\hline 165 & $\begin{array}{r}\text { Nov ‘04 } \\
\text { /96 }\end{array}$ & $\begin{array}{r}\text { Control } \\
\text { DSW }\end{array}$ & $\begin{array}{c}<0.002 \\
\text { nd }\end{array}$ & $\begin{array}{l}\text { nd } \\
\text { nd }\end{array}$ & $\begin{array}{l}0.018 \pm 0.003 \\
0.109 \pm 0.001\end{array}$ & $\begin{array}{l}-0.005 \pm 0.003 \\
-0.013 \pm 0.017\end{array}$ & $\begin{array}{l}0.84 \pm 0.02 \\
3.29 \pm 0.07\end{array}$ & $\begin{array}{l}0.05 \pm 0.02 \\
1.15 \pm 0.01\end{array}$ \\
\hline 167 & $\begin{array}{r}\text { Feb ‘05 } \\
/ 110\end{array}$ & $\begin{array}{r}\text { Control } \\
\text { DSW }\end{array}$ & $\begin{array}{c}<0.002 \\
\text { nd }\end{array}$ & $\begin{array}{l}\text { nd } \\
\text { nd }\end{array}$ & $\begin{array}{l}0.030 \pm 0.001 \\
0.179 \pm 0.001\end{array}$ & $\begin{array}{l}-0.009 \pm 0.001 \\
-0.036 \pm 0.002\end{array}$ & $\begin{array}{l}0.80 \pm 0.08 \\
4.89 \pm 0.07\end{array}$ & $\begin{array}{l}-0.01 \pm 0.03 \\
-0.25 \pm 0.04\end{array}$ \\
\hline 174 & $\begin{array}{r}\text { Oct }{ }^{\prime} 05 \\
/ 96\end{array}$ & $\begin{array}{r}\text { Control } \\
\text { DSW }\end{array}$ & $\begin{array}{c}0.005 \\
1.81\end{array}$ & $\begin{array}{c}\text { nd } \\
-0.53\end{array}$ & $\begin{array}{l}0.018 \pm 0.000 \\
0.138 \pm 0.002\end{array}$ & $\begin{array}{l}-0.007 \pm 0.000 \\
-0.040 \pm 0.002\end{array}$ & $\begin{array}{l}0.98 \pm 0.01 \\
5.14 \pm 0.10\end{array}$ & $\begin{array}{c}\text { nd } \\
0.02\end{array}$ \\
\hline 175 & $\begin{array}{r}\text { Nov ‘05 } \\
/ 170\end{array}$ & $\begin{array}{r}\text { Control } \\
\text { DSW }\end{array}$ & $\begin{array}{l}0.005 \\
1.84\end{array}$ & $\begin{array}{c}0.00 \\
-0.93\end{array}$ & $\begin{array}{l}0.045 \pm 0.002 \\
0.181 \pm 0.003\end{array}$ & $\begin{array}{l}-0.009 \pm 0.002 \\
-0.074 \pm 0.005\end{array}$ & $\begin{array}{l}1.01 \pm 0.02 \\
5.15 \pm 0.05\end{array}$ & $\begin{array}{l}-0.15 \pm 0.02 \\
-0.69 \pm 0.07\end{array}$ \\
\hline 183 & $\begin{array}{r}\text { Jul ‘06 } \\
\text { /144 }\end{array}$ & $\begin{array}{r}\text { Control } \\
\text { DSW }\end{array}$ & $\begin{array}{c}0.006 \\
1.82\end{array}$ & $\begin{array}{l}-0.001 \\
-1.82\end{array}$ & $\begin{array}{l}0.072 \pm 0.001 \\
0.173 \pm 0.005\end{array}$ & $\begin{array}{l}-0.006 \pm 0.001 \\
-0.122 \pm 0.006\end{array}$ & $\begin{array}{l}1.04 \pm 0.03 \\
6.16 \pm 0.11\end{array}$ & $\begin{array}{l}-0.03 \pm 0.03 \\
-3.30 \pm 0.11\end{array}$ \\
\hline 186 & $\begin{array}{r}\text { Oct ‘06 } \\
/ 120\end{array}$ & $\begin{array}{r}\text { Control } \\
\text { DSW } \\
\mathrm{N} \text { only }\end{array}$ & $\begin{array}{c}0.004 \\
2.44 \\
2.24\end{array}$ & $\begin{array}{c}\text { nd } \\
-0.74 \\
-0.89\end{array}$ & $\begin{array}{l}0.016 \pm 0.001 \\
0.170 \pm 0.002 \\
0.021 \pm 0.001\end{array}$ & $\begin{array}{r}0.002 \pm 0.001 \\
-0.065 \pm 0.003 \\
-0.011 \pm 0.001\end{array}$ & $\begin{array}{l}1.24 \pm 0.03 \\
5.71 \pm 0.05 \\
1.05 \pm 0.02\end{array}$ & $\begin{array}{r}-0.25 \pm 0.02 \\
3.35 \pm 0.15 \\
-0.04 \pm 0.01\end{array}$ \\
\hline 191 & $\begin{array}{r}\text { May ‘07 } \\
\text { /120 }\end{array}$ & $\begin{array}{r}\text { Control } \\
\text { DSW } \\
\mathrm{N} \text { only }\end{array}$ & $\begin{array}{l}0.009 \\
2.06 \\
2.05\end{array}$ & $\begin{array}{l}-0.002 \\
-2.05 \\
-1.94\end{array}$ & $\begin{array}{l}0.113 \pm 0.003 \\
0.241 \pm 0.004 \\
0.113 \pm 0.003\end{array}$ & $\begin{array}{l}-0.018 \pm 0.005 \\
-0.154 \pm 0.004 \\
-0.081 \pm 0.002\end{array}$ & $\begin{array}{l}0.90 \pm 0.01 \\
5.02 \pm 0.12 \\
0.93 \pm 0.06\end{array}$ & $\begin{array}{r}0.04 \pm 0.01 \\
-1.12 \pm 0.11 \\
-0.38 \pm 0.01\end{array}$ \\
\hline
\end{tabular}

during experiments conducted in October 2004 and February 2005 due to cloud cover (Table 1). Ambient concentrations of nitrate and silicate were typically low and showed no discernible temporal pattern (Table 2), although strong seasonality is observed in climatological nitrate (Fig. 1c). Ambient concentrations of phosphate were significantly higher $(>0.07$ $\left.\mu \mathrm{mol} \mathrm{l}^{-1}, \mathrm{p}<0.05\right)$ during May and July experiments (Table 2), which is consistent with Station ALOHA climatology (Fig. 1d), although surface water phosphate concentrations in May 2007 were significantly higher than the climatological monthly average (Fig. 1d). Chl a concentrations in incubation bottles at $T_{0}$ ranged from 0.03 to $0.13 \mu \mathrm{g} \mathrm{l}^{-1}$ (Table 3) but were 25 to $50 \%$ higher between July 2004 and February 2005 (mean $\pm \mathrm{SD}_{i} 0.11 \pm 0.02 \mu \mathrm{g} \mathrm{l^{-1 }}, \mathrm{n}=5$ ) compared to concentrations measured between October 2005 and May $2007\left(0.06 \pm 0.02 \mu \mathrm{g} \mathrm{l} \mathrm{l}^{-1}, \mathrm{n}=5\right)$. However, there was no significant difference in chl a concentration at $30 \mathrm{~m}$ at Station ALOHA between these time periods $\left(0.090 \pm 0.023\right.$ vs. $\left.0.094 \pm 0.018 \mu \mathrm{g} \mathrm{l}^{-1}\right)$. The difference in chl $a$ in the incubations has been attributed to the use of 2 fluorometers (Turner Designs TD700 vs. 10-AU), which have different responses to the presence of pigments other than chl $a$. Thus, we cannot compare chl $a$ in incubation bottles at $T_{0}$ between experiments but instead compare the relative change in chl a concentrations within each experiment. CF rates at $T_{0}\left(3.8\right.$ to $\left.8.9 \mu \mathrm{g} \mathrm{Cl}^{-1} \mathrm{~d}^{-1}\right)$ were significantly higher during July $2004(\mathrm{p}<0.05)$ and lowest during November 2004 and 2005 (Table 3) but were within the $20 \mathrm{yr}$ climatology observed at Station ALOHA. As expected from the climatology, the $0.2-$ $2 \mu \mathrm{m}$ size fraction dominated both chl a $(87 \pm 4 \%)$ and rates of CF $(66 \pm 9 \%)$, with $2-10 \mu \mathrm{m}$ and $>10 \mu \mathrm{m}$ size fractions accounting for $8 \pm 2$ and $5 \pm 2 \%$, respectively, of tchl $a$ and $5 \pm 2$ and $8 \pm 5 \%$, respectively of $\mathrm{CF}$ rates (Table 4). In agreement with previous observations at Station ALOHA, N-PB $(4.08$ to $4.58 \times$ $\left.10^{5} \mathrm{ml}^{-1}\right)$ and PRO (1.83 to $\left.2.43 \times 10^{5} \mathrm{ml}^{-1}\right)$ were the most abundant microbes at the beginning of each experiment, although PRO cell abundance was higher than expected during November 2005 (2.43 × $10^{5} \mathrm{ml}^{-1}$ ) and N-PB abundance was lower than expected during July $2006\left(2.55 \times 10^{5} \mathrm{ml}^{-1}\right.$, Table 5). The abundance of the SYN $\left(0.95\right.$ to $\left.1.28 \times 10^{3} \mathrm{ml}^{-1}\right)$ and PEUK ( 0.46 to $\left.0.72 \times 10^{3} \mathrm{ml}^{-1}\right)$ were also in agreement with previous observations $(1.70 \pm 1.10$ and 0.72 $\pm 0.36 \times 10^{3} \mathrm{ml}^{-1}$, respectively, Landry \& Kirchman 2002), although in May 2007, SYN and PEUK were 
more than double that observed throughout the rest of the year $\left(2.99\right.$ and $1.72 \times 10^{3} \mathrm{ml}^{-1}$, respectively, Table 5). The concentration of fucoxanthin (3 to $5 \mathrm{ng}$ $\mathrm{l}^{-1}$ ) and the relative contribution of fucoxanthin to tchl $a$ in control incubations at $T_{0}$ (3 to $8 \%$, Table 5) were typical of those reported at $\sim 30 \mathrm{~m}$ at Station ALOHA $\left(\right.$ mean \pm SD from 1988 to 2009, $7 \pm 9 \mathrm{ng} \mathrm{l}^{-1}$ and $9 \pm$ $15 \%, \mathrm{n}=248$; http://hahana.soest.hawaii.edu/hot/ hot-dogs/interface.html). Comparison of nutrient concentrations, community structure, and rate measurements in control incubations and water column measurements from the HOT cruises were not significantly different $(p>0.05)$ implying that initial conditions and community structure in the incubation experiments reflected the typical water column ecosystem.

\section{Control incubations}

Overall, the changes in nutrients, tchl a and total rates of $\mathrm{CF}$ in control incubations were statistically insignificant $(\mathrm{p}>0.05)$ in comparison to changes observed in treatment incubations (Tables 2 \& 3).
Nitrate concentrations decreased by $<0.005 \mu \mathrm{mol} \mathrm{l}^{-1}$ from a maximum concentration of $0.009 \mu \mathrm{mol} \mathrm{l}^{-1}$ (Fig. 2a, Table 2). Phosphate concentrations decreased by $<0.009 \mu \mathrm{mol} \mathrm{l}^{-1}$ in experiments conducted between September and February but by 0.018 to $0.048 \mu \mathrm{mol} \mathrm{l}^{-1}$ in May and July experiments, representing $16 \%$ and $50 \%$ reductions relative to the initial phosphate concentrations in winter and summer experiments, respectively (Fig. 2c, Table 2). Silicate concentrations increased by $0.04 \mu \mathrm{mol} \mathrm{l}^{-1}$ and $0.22 \mu_{\mathrm{mol} \mathrm{l}} \mathrm{l}^{-1}$ in May 2007 and July 2004 experiments, respectively, but decreased by 0.03 to $0.25 \mu \mathrm{mol} \mathrm{l}^{-1}$ during the remaining experiments (Fig. 2e, Table 2). Chl a concentrations increased in control incubations during 5 experiments (by between 0.02 to $0.15 \mu \mathrm{g} \mathrm{l}^{-1}$ ) and decreased during 5 experiments (by between 0.01 to $0.04 \mu g \mathrm{l}^{-1}$ ), but there was no significant change in the size distribution of chl $a$ in the control incubations ( $p>0.05$, Table 4). Whole community growth rates $(\mu)$ ranged from -0.11 to $0.13 \mathrm{~d}^{-1}$ in control incubations (Table 3) and were not significantly different between size fractions $(0.2-2 \mu \mathrm{m}=0.09 \pm$ $0.03 \mathrm{~d}^{-1} ; 2-10 \mu \mathrm{m}=0.05 \pm 0.03 \mathrm{~d}^{-1} ;>10 \mu \mathrm{m}=0.13 \pm$ $0.09 \mathrm{~d}^{-1}$; Table 4). Total rates of CF in control incuba-

Table 3. Mean $\pm 1 \mathrm{SD}$ of initial properties at time $0\left(T_{0}\right)$ and change in properties at the end of the experiment $\left(\Delta T_{\mathrm{f}}\right)$ in control and treatment incubations (4.5\% vol:vol deep seawater [DSW] and nitrate only [N only]). Properties include total chlorophyll a concentrations (tchl a), carbon fixation rates $(\mathrm{CF})$, and growth rate $(\mu)$. Negative values signify a decrease in a property. Values in brackets represent the change in a property between $T_{0}$ and the time of maximum concentration or rate ( $\left.T_{\text {peak }}\right) ;$ otherwise, maximum changes were between $T_{0}$ and $T_{\mathrm{f}}$

\begin{tabular}{|c|c|c|c|c|c|c|c|}
\hline Cruise & Date & Carboy & $\begin{array}{l}\operatorname{tchl} \text { a } T_{0} \\
\left(\mu \mathrm{g} \mathrm{l}^{-1}\right)\end{array}$ & $\begin{array}{l}\Delta \operatorname{tchl} a T_{\mathrm{f}} \\
\left(\mu \mathrm{g} \mathrm{l}^{-1}\right)\end{array}$ & $\begin{array}{c}\mathrm{CF} T_{0} \\
\left(\mu \mathrm{g} \mathrm{l}^{-1} \mathrm{~d}^{-1}\right)\end{array}$ & $\begin{array}{c}\Delta \mathrm{CF} T_{\mathrm{f}} \\
\left(\mu \mathrm{g} \mathrm{l}^{-1} \mathrm{~d}^{-1}\right)\end{array}$ & $\begin{array}{c}\text { Growth rate } \\
\mu,\left(\mathrm{d}^{-1}\right)\end{array}$ \\
\hline 161 & Jul ‘04 & $\begin{array}{r}\text { Control } \\
\text { DSW }\end{array}$ & $\begin{array}{l}0.10 \\
0.08\end{array}$ & $\begin{array}{l}0.07 \\
0.63\end{array}$ & $\begin{array}{c}8.9 \pm 0.03 \\
13.3 \pm 7.6\end{array}$ & $\begin{array}{c}15.6 \pm 7.1 \\
122.9 \pm 16.4\end{array}$ & $\begin{array}{l}0.11 \\
0.44\end{array}$ \\
\hline 163 & Sep ‘04 & $\begin{array}{r}\text { Control } \\
\text { DSW }\end{array}$ & $\begin{array}{l}0.10 \\
0.12\end{array}$ & $\begin{array}{l}0.06 \\
0.32(0.43)\end{array}$ & $\begin{array}{l}5.3 \pm 0.2 \\
6.1 \pm 0.3\end{array}$ & $\begin{array}{r}3.0 \pm 2.9 \\
35.3 \pm 5.4\end{array}$ & $\begin{array}{l}0.09 \\
0.25(0.29)\end{array}$ \\
\hline 164 & Oct ‘04 & $\begin{array}{r}\text { Control } \\
\text { DSW }\end{array}$ & $\begin{array}{l}0.09 \\
0.10\end{array}$ & $\begin{array}{l}0.05(0.15) \\
0.01(0.27)\end{array}$ & $\begin{array}{l}6.4 \pm 0.1 \\
6.4 \pm 0.2\end{array}$ & $\begin{array}{l}0.5 \pm 1.9(2.5 \pm 1.3) \\
8.7 \pm 8.4(31.2 \pm 8.7)\end{array}$ & $\begin{array}{l}0.08(0.13) \\
0.01(0.32)\end{array}$ \\
\hline 165 & Nov ‘04 & $\begin{array}{r}\text { Control } \\
\text { DSW }\end{array}$ & $\begin{array}{l}0.13 \\
0.13\end{array}$ & $\begin{array}{r}-0.02 \\
0.30\end{array}$ & $\begin{array}{l}3.8 \pm 0.9 \\
4.6 \pm 0.1\end{array}$ & $\begin{array}{r}0.4 \pm 0.7 \\
31.2 \pm 4.9\end{array}$ & $\begin{array}{r}-0.03 \\
0.30\end{array}$ \\
\hline 167 & Feb ‘05 & $\begin{array}{r}\text { Control } \\
\text { DSW }\end{array}$ & $\begin{array}{l}0.13 \\
0.13\end{array}$ & $\begin{array}{r}-0.01 \\
0.24\end{array}$ & $\begin{array}{l}5.4 \pm 0.6 \\
6.5 \pm 0.3\end{array}$ & $\begin{array}{r}0.1 \pm 0.3 \\
20.4 \pm 3.5\end{array}$ & $\begin{array}{r}-0.02 \\
0.22\end{array}$ \\
\hline 174 & Oct ‘05 & $\begin{array}{r}\text { Control } \\
\text { DSW }\end{array}$ & $\begin{array}{l}0.09 \\
0.09\end{array}$ & $\begin{array}{r}-0.04 \\
0.29\end{array}$ & $\begin{array}{l}3.9 \\
4.0\end{array}$ & $\begin{array}{r}0.3 \\
14.7\end{array}$ & $\begin{array}{r}-0.10(-0.12) \\
0.29(0.18)\end{array}$ \\
\hline 175 & Nov ‘05 & $\begin{array}{r}\text { Control } \\
\text { DSW }\end{array}$ & $\begin{array}{l}0.08 \\
0.09\end{array}$ & $\begin{array}{r}-0.04 \\
0.12\end{array}$ & $\begin{array}{l}3.8 \pm 0.6 \\
3.9 \pm 0.5\end{array}$ & $\begin{array}{l}-0.7 \pm 0.4 \\
33.1 \pm 1.2\end{array}$ & $\begin{array}{r}-0.08 \\
0.13\end{array}$ \\
\hline 183 & Jul ‘06 & $\begin{array}{r}\text { Control } \\
\text { DSW }\end{array}$ & $\begin{array}{l}0.07 \\
0.07\end{array}$ & $\begin{array}{l}0.04 \\
0.58(0.98)\end{array}$ & $\begin{array}{l}5.0 \pm 0.3 \\
8.7 \pm 0.9\end{array}$ & $\begin{array}{l}-1.6 \pm 0.3 \\
15.8 \pm 2.5(111.6 \pm 6.2)\end{array}$ & $\begin{array}{c}-0.08(-0.13) \\
0.38(0.55)\end{array}$ \\
\hline 186 & Oct ‘06 & $\begin{array}{r}\text { Control } \\
\text { DSW } \\
\mathrm{N} \text { only }\end{array}$ & $\begin{array}{l}0.05 \\
0.05 \\
0.05\end{array}$ & $\begin{array}{r}-0.02 \\
0.09 \\
0.09\end{array}$ & $\begin{array}{l}5.0 \pm 0.2 \\
4.7 \pm 0.3 \\
6.1\end{array}$ & $\begin{array}{l}-3.0 \pm 0.2 \\
12.3 \pm 1.7 \\
7.9(10.3)\end{array}$ & $\begin{array}{l}-0.11(-0.04) \\
0.20(0.30) \\
0.20\end{array}$ \\
\hline 191 & May ‘07 & $\begin{array}{r}\text { Control } \\
\text { DSW } \\
\mathrm{N} \text { only }\end{array}$ & $\begin{array}{l}0.03 \\
0.03 \\
0.03\end{array}$ & $\begin{array}{l}0.02 \\
0.46(0.58) \\
0.30(0.37)\end{array}$ & $\begin{array}{l}4.6 \\
5.9 \\
5.0\end{array}$ & $\begin{array}{l}-1.3 \pm 0.3 \\
31.6 \pm 3.9(74.8 \pm 4.5) \\
33.4(49.7)\end{array}$ & $\begin{array}{l}0.08(0.10) \\
0.54(0.73) \\
0.46(0.51)\end{array}$ \\
\hline
\end{tabular}


Table 4. Percentage (\%) contribution of the $0.2-2 \mu \mathrm{m}, 2-10 \mu \mathrm{m}$ and $>10 \mu \mathrm{m}$ size fractions to total chlorophyll a concentrations (SF-chl a), carbon fixation rates (SF-CF rate), and growth rates $\left(\mu, \mathrm{d}^{-1}\right)$ at time $0\left(T_{0}\right)$ and at the final point ( $\left.T_{\mathrm{f}}\right)$ in control and treatment incubations $(4.5 \%$ vol:vol deep seawater [DSW] and nitrate only [N only]. Values in brackets are the maximum growth rates observed; otherwise, maximum growth rates were at $T_{\mathrm{f}} \cdot \mu$ was calculated according to Fogg \& Thake (1987)

\begin{tabular}{|c|c|c|c|c|c|c|c|c|c|c|c|c|}
\hline \multirow[t]{2}{*}{ Cruise } & \multirow[t]{2}{*}{ e Date } & \multirow[t]{2}{*}{ Carboy } & \multirow{2}{*}{$\begin{array}{l}\text { Time } \\
\text { point }\end{array}$} & \multicolumn{3}{|c|}{ SF-chl a (\%) } & \multicolumn{3}{|c|}{ SF-CF rate $(\%)$} & \multicolumn{3}{|c|}{ Growth rate $\mu\left(\mathrm{d}^{-1}\right)$} \\
\hline & & & & $0.2-2 \mu \mathrm{m}$ & $2-10 \mu \mathrm{m}$ & $>10 \mu \mathrm{m}$ & $0.2-2 \mu \mathrm{m}$ & $2-10 \mu \mathrm{m}$ & $>10 \mu \mathrm{m}$ & $0.2-2 \mu \mathrm{m}$ & $2-10 \mu \mathrm{m}$ & $>10 \mu \mathrm{m}$ \\
\hline \multirow[t]{2}{*}{174} & Oct ‘05 & Control & $T_{0}$ & 88 & 8 & 4 & 64 & 25 & 11 & -0.11 & -0.05 & -0.02 \\
\hline & & Control & $T_{\mathrm{f}}$ & 84 & 10 & 6 & 32 & 38 & 30 & & & \\
\hline \multirow[t]{2}{*}{174} & Oct ‘05 & DSW & $T_{0}$ & 90 & 6 & 3 & 49 & 35 & 16 & 0.26 & 0.45 & 0.36 \\
\hline & & DSW & $T_{\mathrm{f}}$ & 80 & 15 & 5 & 45 & 33 & 22 & & & \\
\hline \multirow[t]{2}{*}{175} & Nov ‘05 & Control & $T_{0}$ & 91 & 6 & 3 & 74 & 17 & 9 & -0.10 & -0.01 & 0.60 \\
\hline & & Control & $T_{\mathrm{f}}$ & 80 & 10 & 9 & 59 & 31 & 10 & & & \\
\hline \multirow[t]{2}{*}{175} & Nov ‘05 & DSW & $T_{0}$ & 90 & 5 & 5 & 75 & 18 & 8 & 0.06 & 0.37 & 0.30 \\
\hline & & DSW & $T_{\mathrm{f}}$ & 55 & 29 & 16 & 11 & 78 & 12 & & & \\
\hline \multirow[t]{2}{*}{183} & Jul `06 & Control & $T_{0}$ & 88 & 5 & 7 & 69 & 31 & 1 & 0.06 & 0.04 & 0.25 \\
\hline & & Control & $T_{\mathrm{f}}$ & 76 & 4 & 20 & 36 & 41 & 23 & & & \\
\hline \multirow[t]{2}{*}{183} & Jul ‘06 & DSW & $T_{0}$ & 88 & 5 & 7 & 69 & 17 & 14 & 0.09 & 0.49 & 0.77 \\
\hline & & DSW & $T_{\mathrm{f}}$ & 16 & 11 & 73 & 13 & 23 & 64 & $(0.26)$ & $(0.88)$ & $(0.95)$ \\
\hline \multirow[t]{2}{*}{186} & Oct ` 06 & Control & $T_{0}$ & 89 & 8 & 3 & 52 & 36 & 13 & -0.13 & -0.05 & 0.11 \\
\hline & & Control & $T_{\mathrm{f}}$ & 80 & 11 & 10 & 54 & 27 & 19 & & & \\
\hline \multirow[t]{2}{*}{186} & Oct `06 & DSW & $T_{0}$ & 89 & 8 & 3 & 49 & 39 & 12 & 0.13 & 0.41 & 0.53 \\
\hline & & DSW & $T_{\mathrm{f}}$ & 62 & 22 & 16 & 40 & 20 & 40 & $(0.30)$ & & \\
\hline \multirow[t]{2}{*}{186} & Oct ‘06 & $\mathrm{N}$ only & $T_{0}$ & 89 & 8 & 3 & 71 & 23 & 6 & 0.18 & 0.26 & 0.41 \\
\hline & & $\mathrm{N}$ only & $T_{\mathrm{f}}$ & 81 & 11 & 9 & 69 & 12 & 19 & & & \\
\hline \multirow[t]{2}{*}{191} & May ‘07 & Control & $T_{0}$ & 81 & 11 & 8 & 72 & 19 & 8 & 0.07 & 0.09 & 0.18 \\
\hline & & Control & $T_{\mathrm{f}}$ & 75 & 12 & 14 & 62 & 21 & 17 & & & \\
\hline \multirow[t]{2}{*}{191} & May '07 & DSW & $T_{0}$ & 81 & 11 & 8 & 77 & 14 & 8 & 0.13 & 0.75 & 0.94 \\
\hline & & DSW & $T_{\mathrm{f}}$ & 10 & 30 & 60 & 21 & 41 & 38 & $(0.62)$ & $(0.96)$ & $(0.98)$ \\
\hline \multirow[t]{2}{*}{191} & May ‘07 & $\mathrm{N}$ only & $T_{0}$ & 81 & 11 & 8 & 80 & 13 & 8 & 0.33 & 0.38 & 0.82 \\
\hline & & $\mathrm{N}$ only & $T_{\mathrm{f}}$ & 42 & 7 & 51 & 33 & 35 & 32 & $(0.36)$ & $(0.65)$ & $(0.83)$ \\
\hline
\end{tabular}

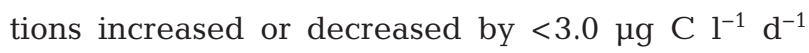
although a large increase in rates of CF of $15.6 \pm 7.1$ $\mu \mathrm{g} \mathrm{C} \mathrm{l}^{-1} \mathrm{~d}^{-1}$ was observed July 2004 (Table 3 ). There was a significant decrease (by 34 to $64 \%$ ) in the $\mathrm{CF}$ rates of the $0.2-2 \mu \mathrm{m}$ size fraction and either no change or a $50 \%$ decrease in CF rates of the 2-10 $\mu \mathrm{m}$ and $>10 \mu \mathrm{m}$ size fractions (Table 4 ). CF by the $2-10$ $\mu \mathrm{m}$ size fraction increased by $50 \%$ in control incubations in October 2005. Indeed, changes in community structure were observed in control incubations. PRO cell abundance decreased significantly $(\mathrm{p}<0.05)$ from a mean $( \pm \mathrm{SD})$ of $2.09 \pm 0.24$ to $0.38 \pm 0.20 \times 10^{5}$ cells $\mathrm{ml}^{-1}$ (or by 68 to $94 \%$, Table 5). N-PB abundance increased from $4.03 \pm 0.86$ to $9.45 \pm 2.83 \times$ $10^{5} \mathrm{ml}^{-1}$ (or by 27 to $91 \%$ ) during control incubations (Table 5). SYN cell abundance decreased by $63 \%$ in one experiment and increased by 50 to $94 \%$ in 3 experiments (Table 5). However, there was no consistent response in PEUK cell abundance in control incubations. Cell abundance doubled (October 2005), halved (July 2006), decreased by an order of magnitude (May 2007), or did not change (October
2006, Table 5). Despite a shift in community structure, the change in total phototrophic biomass and activity was negligible, and therefore the effects of containment were considered to be minor.

\section{Response of microbial community to DSW addition}

The addition of $\sim 4.5 \%$ DSW (vol:vol) increased the nitrate concentration by 3 orders of magnitude (1.81 to $2.44 \mu \mathrm{mol} \mathrm{l}^{-1}$ ), phosphate by 2 - to 10 -fold ( 0.109 to $0.257 \mathrm{mmol} \mathrm{l}^{-1}$, the range being due to variable ambient phosphate concentrations in surface waters) and silicate by 4 - to 6 -fold ( 3.29 to $6.16 \mu \mathrm{mol} \mathrm{l}^{-1}$ ) in treatment incubations relative to the ambient concentration (Table 2). Overall, there was consistent response to DSW addition in treatment incubations, including increased chl $a$, increased rates of $\mathrm{CF}$, changes in community composition and size structure, and eventual nutrient drawdown. However, the magnitude of the response varied significantly $(p<0.05)$ between groups of experiments. 

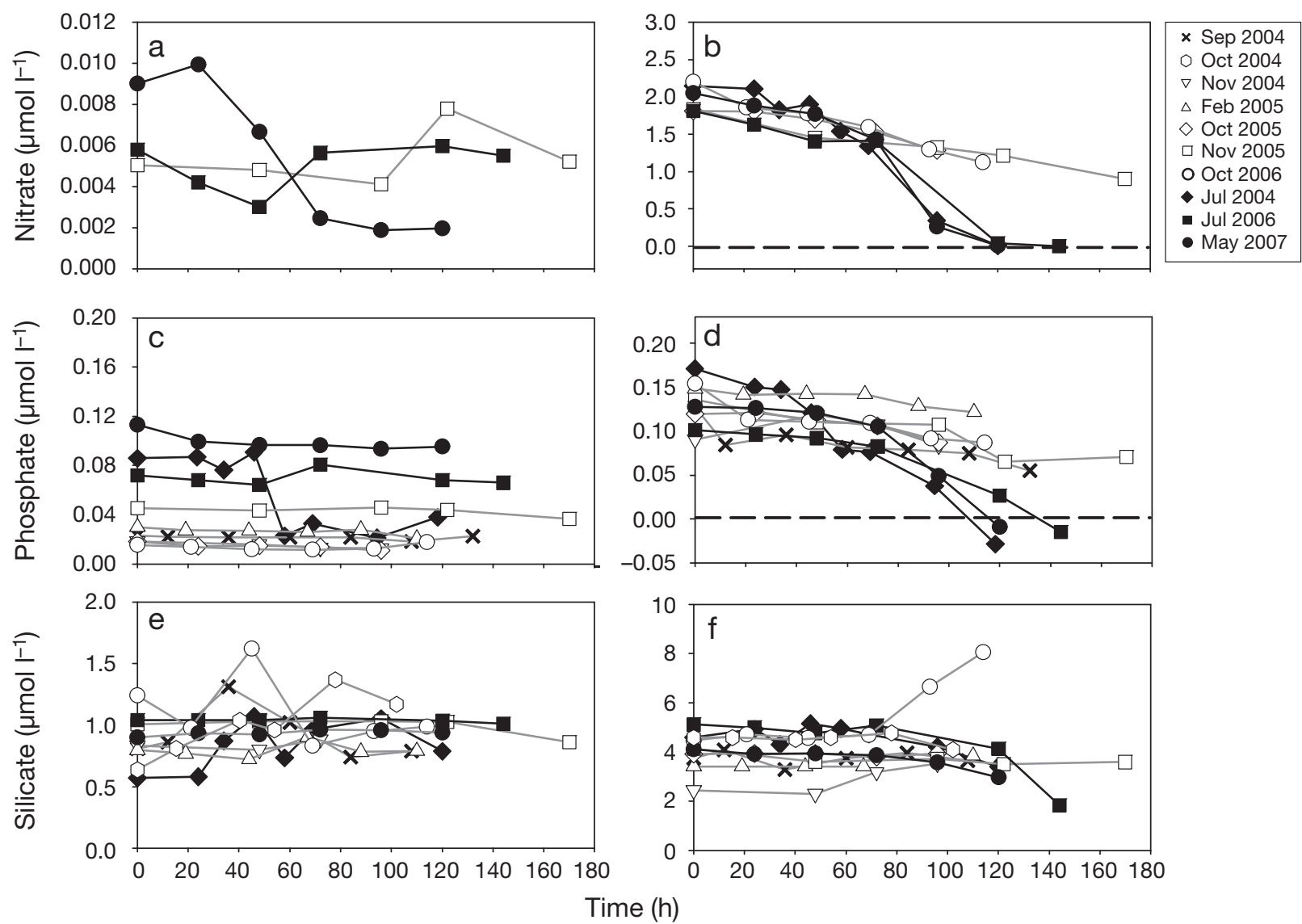

Fig. 2. Nutrient concentrations from each time point sampled during the experiments: nitrate in (a) control and (b) controlcorrected treatment; phosphate in (c) control and (d) control-corrected treatment; and silicate in (e) control and (f) controlcorrected treatment. Experiments conducted in winter have open symbols; those conducted in summer have filled symbols.

Dashed lines indicate when nutrient concentration in the treatment and control incubations were equal

\section{Nutrients}

In experiments conducted in winter, 29 to $51 \%$ and 12 to $48 \%$ of the initial total nitrate and phosphate (ambient nutrient plus nutrient introduced through DSW addition) were removed in treatment incubations by $T_{\mathrm{f}}$ (Fig. 2b,d respectively, Table 2). In contrast, in experiments conducted in the summer months, nitrate and phosphate that was added to the carboys was completely removed in treatment incubations by $T_{\mathrm{f}}$ (Fig. 2b,d). Phosphate concentrations at $T_{\mathrm{f}}$ were below the initial phosphate concentrations at $T_{0}$, meaning that the added phosphate plus some of the ambient phosphate pool were assimilated during the summertime experiments (Fig. 2d, Table 2). Silicate concentrations remained constant or decreased by a maximum of $13 \%$ during experiments conducted in winter (September 2004, February 2005, and November 2005) but decreased by 22 to $54 \%$ during experiments conducted in summer (Fig. 2f, Table 2). The increase in silicate concentrations dur- ing 3 winter experiments (October 2004, November 2004, October 2006) is unexplainable and is excluded from further interpretation.

\section{Chlorophyll a, growth rates and carbon fixation}

Total chl a concentrations increased up to 4 -fold (0.09 to $\left.0.43 \mu \mathrm{g} \mathrm{l}^{-1}\right)$ in experiments conducted in winter (Fig. 3b-g, i, Table 3). In contrast, there was an 8to 15 -fold $\left(0.46\right.$ to $\left.0.63 \mu \mathrm{g} \mathrm{l}^{-1}\right)$ increase in tchl a concentrations between $T_{0}$ and $T_{\mathrm{f}}$ in summer experiments, although the maximum concentration was observed prior to $T_{\mathrm{f}}$ in July 2006 and May 2007 (Fig. 3h,j, respectively, Table 3).

Whole community growth rates $(\mu)$ in treatment incubations were significantly higher $(p<0.05)$ in experiments conducted in summer months (mean \pm $1 \mathrm{SD}: 0.45 \pm 0.08 \mathrm{~d}^{-1}$ at $T_{\mathrm{f}}, 0.57 \pm 0.15 \mathrm{~d}^{-1}$ at $\left.T_{\text {peak }}\right)$ compared to winter months $\left(0.20 \pm 0.10 \mathrm{~d}^{-1}\right.$, Table 3$)$. Rates of CF showed a similar pattern. In winter 
Table 5. Cell abundance of Prochlorococcus (PRO), non-pigmented bacteria (N-PB), Synechococcus (SYN) and picoeukaryotes (PEUK), and concentration of fucoxanthin, and percentage contribution of fucoxanthin to total chlorophyll a (Fuco/tchl a) at the start $\left(T_{0}\right)$ and final time point $\left(T_{\mathrm{f}}\right)$ of the treatment incubations (4.5\% vol:vol deep seawater [DSW] and nitrate only [N only]). Values in brackets represent the maximum cell abundance, fucoxanthin concentration or contribution of fucoxanthin to total chlorophyll $a_{\text {; }}$ otherwise, maximum values were at $T_{\mathrm{f}}$. nd: not determined

\begin{tabular}{|c|c|c|c|c|c|c|c|c|c|}
\hline Cruise & Date & Carboy & $\begin{array}{l}\text { Time } \\
\text { point }\end{array}$ & $\begin{array}{l}\text { PRO }\left(10^{5}\right. \\
\left.\text { cells } \mathrm{ml}^{-1}\right)\end{array}$ & $\begin{array}{l}\text { N-PB }\left(10^{5}\right. \\
\left.\text { cells } \mathrm{ml}^{-1}\right)\end{array}$ & $\begin{array}{l}\text { SYN }\left(10^{3}\right. \\
\left.\text { cells ml }{ }^{-1}\right)\end{array}$ & $\begin{array}{l}\text { PEUK }\left(10^{3}\right. \\
\left.\text { cells } \mathrm{ml}^{-1}\right)\end{array}$ & $\begin{array}{l}\text { Fucoxanthin } \\
\qquad\left(\mathrm{ng} \mathrm{l}^{-1}\right)\end{array}$ & $\begin{array}{c}\text { Fuco/tchl } a \\
(\%)\end{array}$ \\
\hline 174 & Oct ‘05 & $\begin{array}{l}\text { Control } \\
\text { Control }\end{array}$ & $\begin{array}{l}T_{0} \\
T_{\mathrm{f}}\end{array}$ & $\begin{array}{l}1.97 \\
0.62(1.73)\end{array}$ & $\begin{array}{l}4.58 \\
5.81\end{array}$ & $\begin{array}{l}1.10 \\
1.42\end{array}$ & $\begin{array}{l}0.49 \\
0.83\end{array}$ & $\begin{array}{l}3 \\
5\end{array}$ & $\begin{array}{l}3 \\
8\end{array}$ \\
\hline 174 & Oct '05 & $\begin{array}{l}\text { DSW } \\
\text { DSW }\end{array}$ & $\begin{array}{l}T_{0} \\
T_{\mathrm{f}}\end{array}$ & $\begin{array}{l}3.46 \\
0.48\end{array}$ & $\begin{array}{l}3.22 \\
4.03(6.57)\end{array}$ & $\begin{array}{l}1.95 \\
2.56\end{array}$ & $\begin{array}{l}0.95 \\
2.25\end{array}$ & $\begin{array}{r}3 \\
49\end{array}$ & $\begin{array}{r}3 \\
11\end{array}$ \\
\hline 175 & Nov '05 & $\begin{array}{l}\text { Control } \\
\text { Control }\end{array}$ & $\begin{array}{l}T_{0} \\
T_{\mathrm{f}}\end{array}$ & $\begin{array}{l}2.44 \\
0.15\end{array}$ & $\begin{array}{l}4.08 \\
7.31\end{array}$ & $\begin{array}{l}0.95 \\
\text { nd }\end{array}$ & $\begin{array}{l}0.72 \\
\text { nd }\end{array}$ & $\begin{array}{l}5 \\
3\end{array}$ & $\begin{array}{l}5 \\
6\end{array}$ \\
\hline 175 & Nov ‘05 & $\begin{array}{l}\text { DSW } \\
\text { DSW }\end{array}$ & $\begin{array}{l}T_{0} \\
T_{\mathrm{f}}\end{array}$ & $\begin{array}{l}2.76 \\
0.49\end{array}$ & $\begin{array}{l}4.14 \\
8.00\end{array}$ & $\begin{array}{l}0.97 \\
0.25\end{array}$ & $\begin{array}{l}1.29 \\
4.44\end{array}$ & $\begin{array}{r}5 \\
43\end{array}$ & $\begin{array}{r}5 \\
19\end{array}$ \\
\hline 183 & Jul ‘06 & $\begin{array}{l}\text { Control } \\
\text { Control }\end{array}$ & $\begin{array}{l}T_{0} \\
T_{\mathrm{f}}\end{array}$ & $\begin{array}{l}1.83 \\
0.24\end{array}$ & $\begin{array}{l}2.56 \\
4.89\end{array}$ & $\begin{array}{l}1.00 \\
1.93\end{array}$ & $\begin{array}{l}0.46 \\
0.27(1.03)\end{array}$ & $\begin{array}{r}5 \\
13\end{array}$ & $\begin{array}{r}7 \\
25\end{array}$ \\
\hline 183 & Jul ‘06 & $\begin{array}{l}\text { DSW } \\
\text { DSW }\end{array}$ & $\begin{array}{l}T_{0} \\
T_{\mathrm{f}}\end{array}$ & $\begin{array}{l}2.08 \\
0.30\end{array}$ & $\begin{array}{l}4.61 \\
7.71\end{array}$ & $\begin{array}{l}1.31 \\
8.14\end{array}$ & $\begin{array}{l}0.48 \\
9.47\end{array}$ & $\begin{array}{c}7 \\
120(484)\end{array}$ & $\begin{array}{r}8 \\
71\end{array}$ \\
\hline 186 & Oct ‘06 & $\begin{array}{l}\text { Control } \\
\text { Control }\end{array}$ & $\begin{array}{l}T_{0} \\
T_{\mathrm{f}}\end{array}$ & $\begin{array}{l}2.02 \\
0.54\end{array}$ & $\begin{array}{l}4.67 \\
6.77\end{array}$ & $\begin{array}{l}1.28 \\
0.47\end{array}$ & $\begin{array}{l}0.65 \\
0.67(0.88)\end{array}$ & $\begin{array}{l}2 \\
4\end{array}$ & $\begin{array}{l}3 \\
7\end{array}$ \\
\hline 186 & Oct '06 & $\begin{array}{l}\text { DSW } \\
\text { DSW }\end{array}$ & $\begin{array}{l}T_{0} \\
T_{\mathrm{f}}\end{array}$ & $\begin{array}{l}2.02 \\
2.43\end{array}$ & $\begin{array}{r}4.67 \\
12.23\end{array}$ & $\begin{array}{r}1.28 \\
24.72\end{array}$ & $\begin{array}{l}0.65 \\
0.28(1.44)\end{array}$ & $\begin{array}{r}2 \\
32\end{array}$ & $\begin{array}{r}3 \\
13\end{array}$ \\
\hline 186 & Oct '06 & $\begin{array}{l}\mathrm{N} \text { only } \\
\mathrm{N} \text { only }\end{array}$ & $\begin{array}{l}T_{0} \\
T_{\mathrm{f}}\end{array}$ & $\begin{array}{l}\text { nd } \\
\text { nd }\end{array}$ & $\begin{array}{l}\text { nd } \\
\text { nd }\end{array}$ & $\begin{array}{l}\text { nd } \\
\text { nd }\end{array}$ & $\begin{array}{l}\text { nd } \\
\text { nd }\end{array}$ & $\begin{array}{r}2 \\
12\end{array}$ & $\begin{array}{l}3 \\
7\end{array}$ \\
\hline 191 & May ‘07 & $\begin{array}{l}\text { Control } \\
\text { Control }\end{array}$ & $\begin{array}{l}T_{0} \\
T_{\mathrm{f}}\end{array}$ & $\begin{array}{l}2.21 \\
0.36\end{array}$ & $\begin{array}{l}4.28 \\
5.76\end{array}$ & $\begin{array}{l}2.99 \\
2.38(4.98)\end{array}$ & $\begin{array}{l}1.72 \\
0.12\end{array}$ & $\begin{array}{l}5 \\
4(8)\end{array}$ & $\begin{array}{l}8 \\
8(11)\end{array}$ \\
\hline 191 & May '07 & $\begin{array}{l}\text { DSW } \\
\text { DSW }\end{array}$ & $\begin{array}{l}T_{0} \\
T_{\mathrm{f}}\end{array}$ & $\begin{array}{l}3.25 \\
0.81\end{array}$ & $\begin{array}{r}4.67 \\
12.76\end{array}$ & $\begin{array}{l}2.99 \\
44.21(63.45)\end{array}$ & $\begin{array}{l}2.20 \\
2.41(14.48)\end{array}$ & $\begin{array}{c}5 \\
37(311)\end{array}$ & $\begin{array}{r}8 \\
47\end{array}$ \\
\hline 191 & May ‘07 & $\begin{array}{l}\mathrm{N} \text { only } \\
\mathrm{N} \text { only }\end{array}$ & $\begin{array}{l}T_{0} \\
T_{\mathrm{f}}\end{array}$ & $\begin{array}{l}\text { nd } \\
\text { nd }\end{array}$ & $\begin{array}{l}\text { nd } \\
\text { nd }\end{array}$ & $\begin{array}{l}\text { nd } \\
\text { nd }\end{array}$ & $\begin{array}{l}\text { nd } \\
\text { nd }\end{array}$ & $\begin{array}{l}5 \\
46(135)\end{array}$ & $\begin{array}{c}8 \\
35(32)\end{array}$ \\
\hline
\end{tabular}

experiments, there was a 4 - to 9-fold increase (or

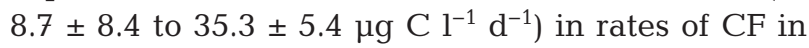
treatment incubations relative to the ambient rate of CF (Fig. 3b-g, i, Table 3). In summer experiments, CF rates increased by 14 - to 22 -fold (or $74.8 \pm 4.5$ to $122.9 \pm 16.4 \mu \mathrm{g} \mathrm{C}^{-1} \mathrm{~d}^{-1}$ ), although the maximum rate occurred prior to $T_{\mathrm{f}}$ during experiments in July 2006 and May 2007 (Fig. 3h,j, respectively, Table 3).

There was a significant shift in the size distribution and activity of the microbial community in treatment incubations in summer compared to winter experiments. In winter experiments, the $0.2-2 \mu \mathrm{m}$ size fraction dominated the tchl a distribution throughout the treatment incubations (55 to $80 \%$ at $T_{\mathrm{f}}$, Fig. $4 \mathrm{a}, \mathrm{c}, \mathrm{g}$ ), whereas in summer experiments, there was an increase in the contribution of the $>10 \mu \mathrm{m}$ size fraction to tchl a (Fig. 4e,i, Table 4), although the 2-10 $\mu \mathrm{m}$ size fraction dominated at $96 \mathrm{~h}$ during the May 2007 experiment (Fig. 4i). There was no significant difference in the growth rates of the $0.2-2 \mu \mathrm{m}$ size fraction in treatment incubations between winter and summer experiments. However, the summertime growth rates of the $2-10 \mu \mathrm{m}\left(0.62 \pm 0.18 \mathrm{~d}^{-1}\right.$ at $T_{\mathrm{f}}, 0.92 \pm 0.05 \mathrm{~d}^{-1}$ at $\left.T_{\text {peak }}\right)$ and $>10 \mu \mathrm{m}\left(0.85 \pm 0.12 \mathrm{~d}^{-1}\right.$ at $T_{\mathrm{f}}, 0.96 \pm 0.03 \mathrm{~d}^{-1}$ at $\left.T_{\text {peak }}\right)$ size fractions were significantly higher $(\mathrm{p}<0.05)$ in treatment incubations compared to wintertime growth rates $\left(2-10 \mu \mathrm{m}=0.41 \pm 0.04 \mathrm{~d}^{-1} ;>10 \mu \mathrm{m}=0.40\right.$ $\pm 0.12 \mathrm{~d}^{-1}$; Table 4). In winter experiments, the absolute rate and relative contribution of each size fraction to total CF rates was almost equal throughout the treatment incubations, except in November 2005, when there was a large increase in the contribution of the $2-10 \mu \mathrm{m}$ size fraction at $T_{\mathrm{f}}$ (Fig. $4 \mathrm{~d}$, Table 4 ). In summer experiments, the contribution of the $2-10 \mu \mathrm{m}$ and $>10 \mu \mathrm{m}$ size fractions to total CF rates increased in treatment incubations (Fig. 4f,j, Table 4).

\section{Community structure}

In a similar manner to the control incubations, PRO cell abundance decreased in all treatment incubations from $2.71 \pm 0.66$ to $0.52 \pm 0.21 \times 10^{5}$ cells ml $^{-1}$ (average decrease of $81 \%$ ), except during October 2006, when PRO cell abundance remained constant throughout the experiment (Table 5). N-PB abundance increased 

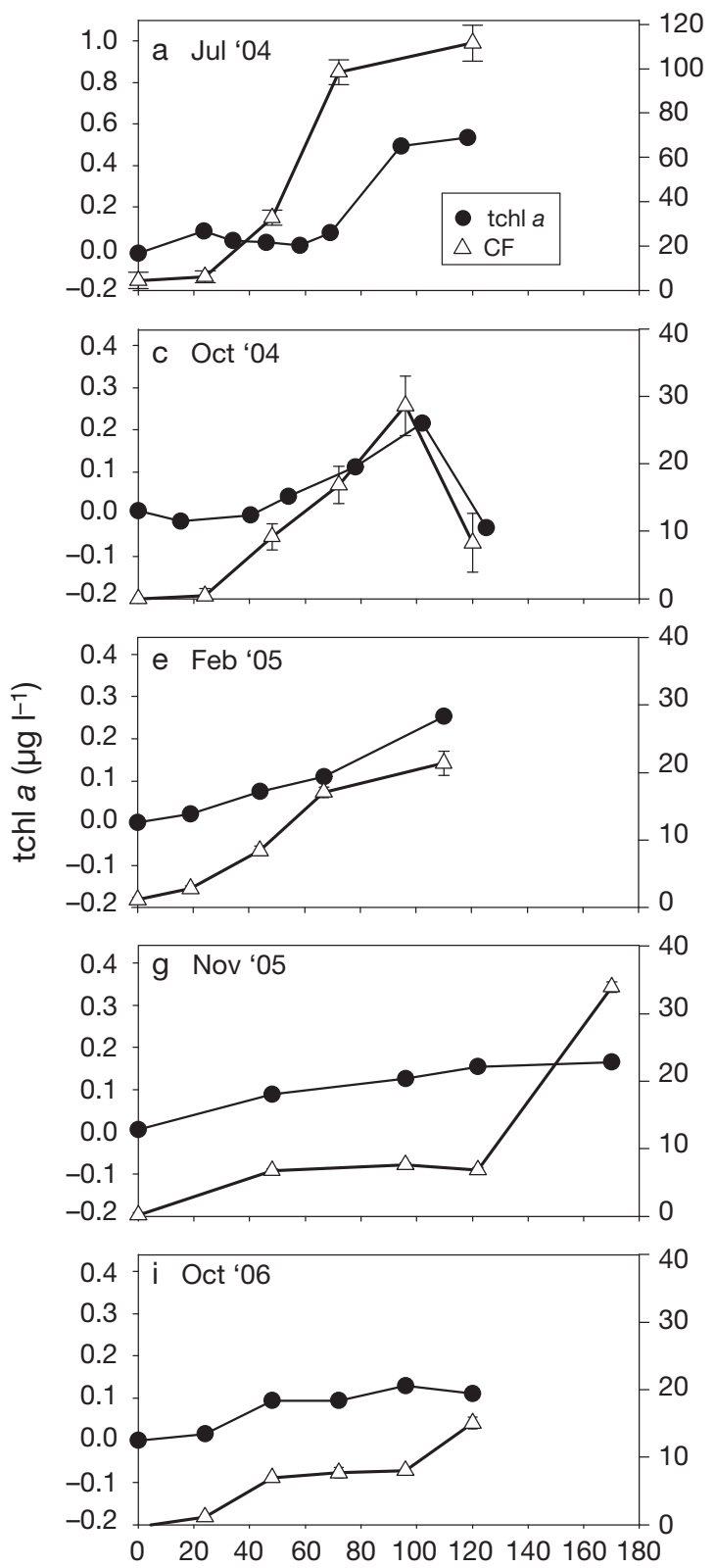

Time (h)
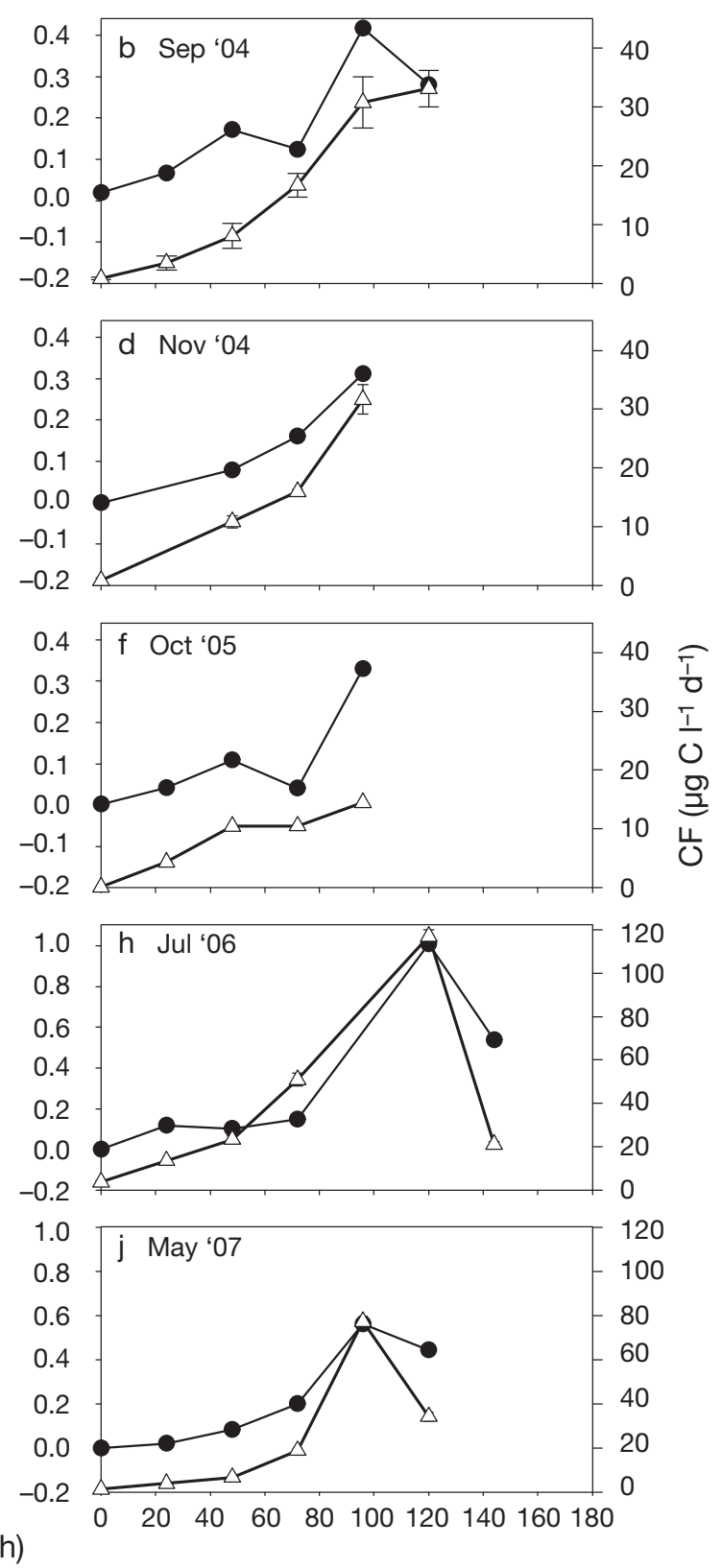

Fig. 3. Total chlorophyll a (tchl a) and rate of carbon fixation (CF) from treatment incubations minus control incubations for each time point sampled. Error bars represent $\pm 1 \mathrm{SD}$ and represent the error of analysis. The CF rate measurement was not replicated in October 2005, and therefore no measurement of error is available. Note, if error bars are not visible, they are smaller than the symbol. Also note the different scale on the $y$-axis for (a), (h), and (j)

by only 2 - to 3 -fold $\left(4.26 \pm 0.62\right.$ to $9.45 \pm 2.83 \times 10^{5}$ cells $\mathrm{ml}^{-1}$ ) in all treatment incubations (Table 5). In winter experiments, SYN and PEUK cell abundance increased 3- to 5-fold and 2- to 3-fold, respectively, between $T_{0}$ and $T_{\mathrm{f}}$ (Table 5). However, there was a 20fold increase in PEUK cell abundance in July 2006 and a 21-fold increase in SYN cell abundance in May 2007 (Table 5). The increase in PEUK abundance in summer was accompanied by a 7 - to 20 -fold (at $T_{\mathrm{f}}$ ) or
59- to 90-fold ( $\left.T_{\text {peak }}\right)$ increase in control corrected fucoxanthin concentrations (Table 5). Fucoxanthin was 47 to $71 \%$ of tchl $a$ at $T_{\mathrm{f}}$ in summer incubations, in comparison to 7 to $8 \%$ at the $T_{0}$ (Fig. $5 \mathrm{a}$, Table 5). In contrast, there was only an 8- to 14 -fold increase in the concentration of fucoxanthin in treatment incubations in winter experiments (Table 5), with fucoxanthin being 11 to $19 \%$ of tchl $a$, in comparison to $<5 \%$ at the start of the experiment (Fig. 5a, Table 5). 


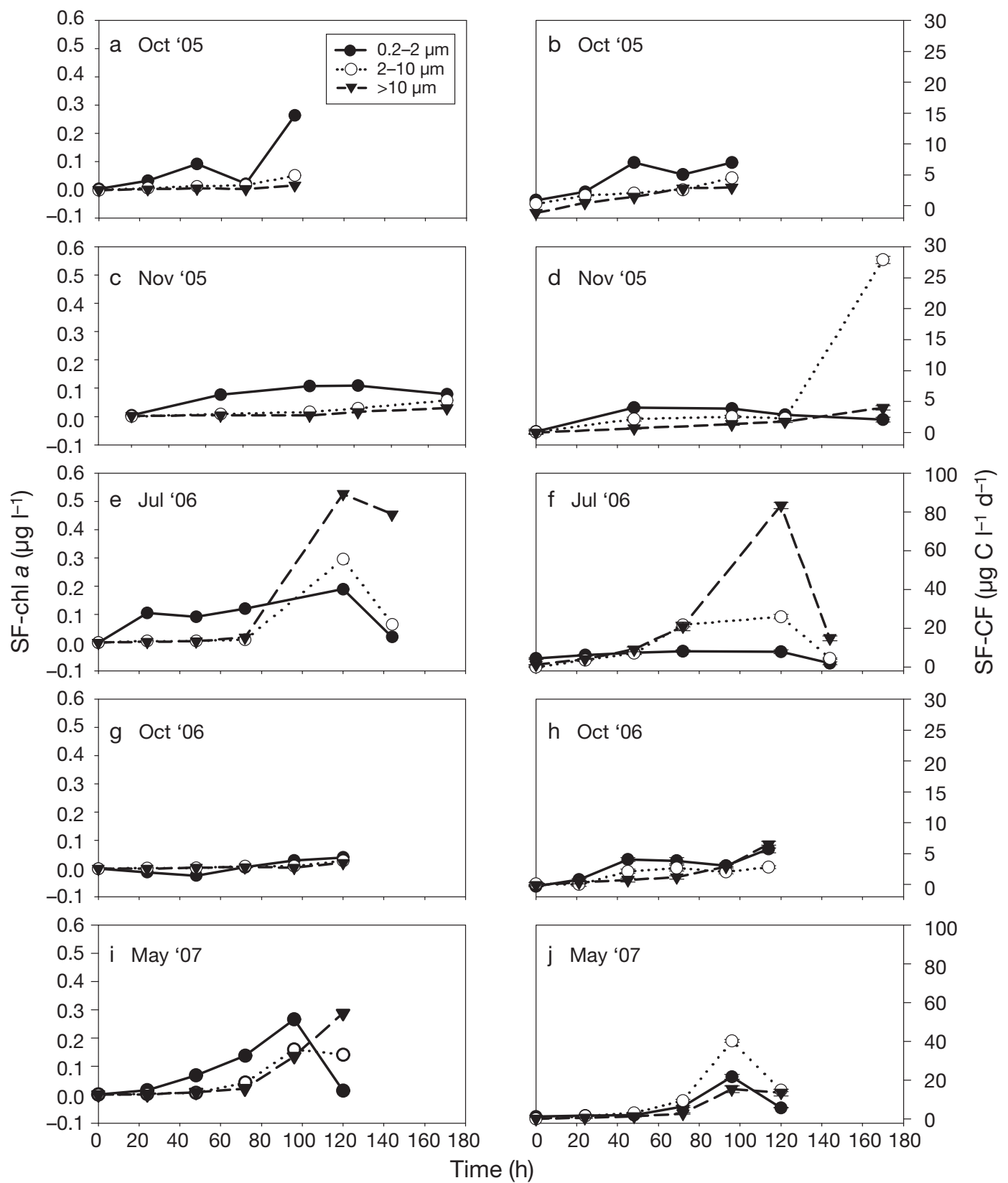

Fig. 4. Size-fractionated $(0.2-2 \mu \mathrm{m}, 2-10 \mu \mathrm{m}$, and $>10 \mu \mathrm{m})$ chlorophyll a (SF-chl $a$, left-hand panels) and rate of carbon fixation (SF-CF, right-hand panels) for treatment incubations minus control incubations for each time point sampled. Error bars on rates of SF-CF represent \pm 1 SD and represent the error of analysis. Note, if not visible, error bars are smaller than the symbol. Also note the different scale on the $y$-axis for (f) and (j)

\section{Response of microbial community to the addition of nitrate}

Initial nitrate concentrations in treatment incubations were $2.24 \mu \mathrm{mol} \mathrm{l}^{-1}$ and $2.05 \mu \mathrm{mol} \mathrm{l}^{-1}$ in October 2006 (winter) and May 2007 (summer), respectively. Phosphate and silicate concentrations were the same as control incubations (Table 2). Between $T_{0}$ and $T_{\mathrm{f}}, 0.89 \mu \mathrm{mol} \mathrm{l}^{-1}(40 \%)$ and $2.05(95 \%) \mu \mathrm{mol} \mathrm{l}^{-1}$ of nitrate were assimilated in winter and summer, respectively (Fig. 6a,b, Table 2), which was comparable to that observed in DSW addition experiments (30\% and $100 \%$, respectively). Phosphate concentrations were reduced by $0.011 \pm 0.001 \mu \mathrm{mol} \mathrm{l}^{-1}(52 \%)$ and $0.081 \pm 0.002 \mu \mathrm{mol} \mathrm{l}^{-1}(72 \%)$ and silicate concentrations were reduced by $0.04 \pm 0.01 \mu \mathrm{mol} \mathrm{l}^{-1}(4 \%)$ and $0.380 \pm 0.010 \mathrm{\mu mol} \mathrm{l}^{-1}(41 \%)$ in winter and summer, respectively (Fig. 6a,b, Table 2). 


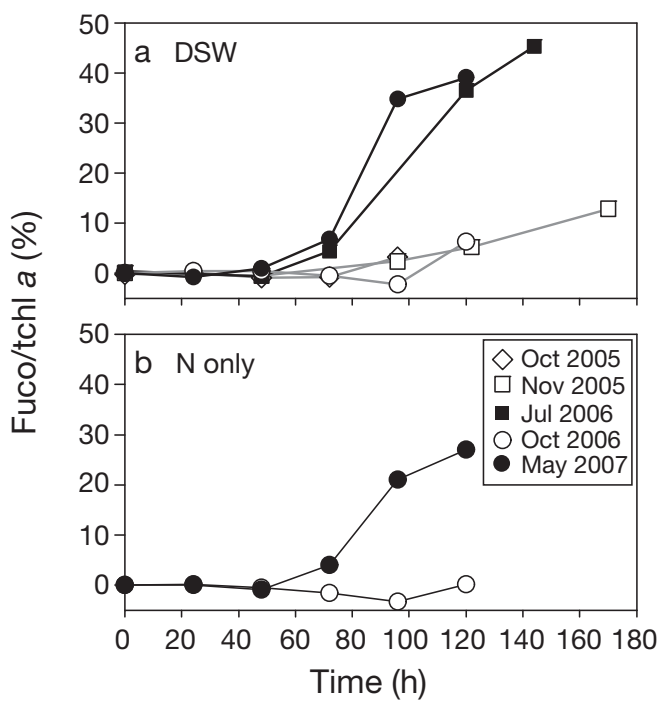

Fig. 5. Concentration of fucoxanthin (Fuco) relative to total chlorophyll a (tchl a), expressed as percent (\%) in treatment incubations minus control incubations during (a) deep sea-water (DSW) addition and (b) nitrate only ( $\mathrm{N}$ only) experiments

Total phototrophic biomass increased 2- and 10-fold and total CF rates increased 2- and 7 -fold in winter and summer nitrate experiments, respectively (Fig. 6c,d, Table 3). In the wintertime experiment, there was a 2- to 3 -fold increase in the contribution of the $0.2-2 \mu \mathrm{m}$ size fraction to both tchl a (Fig. 6e) and total CF rates (Fig. 6g). In the summertime experiment, there was a 5-, 6-, and 60-fold increase in the concentration of chlorophyll in the $0.2-2 \mu \mathrm{m}, 2-10$ $\mu \mathrm{m}$, and $>10 \mu \mathrm{m}$ size fractions, respectively, (Fig. 6f), altering the autotrophic size composition (Table 4). In addition, there was a 10 -fold increase in the CF rate of the $0.2-2$ and $2-10 \mu \mathrm{m}$ size fractions, respectively, but a 32-fold increase in the CF rate of the $>10 \mu \mathrm{m}$ size fraction (Fig. 6h). Fucoxanthin concentrations increased 5-fold in the winter experiment compared to 9- (at $T_{\mathrm{f}}$ ) or 26-fold (at $T_{\text {peak }}$ ) in the summer experiment (Table 5). The contribution of fucoxanthin to tchl $a$ increased from 3 to $7 \%$ in the winter experiment but from 8 to $35 \%$ (32\% fucoxanthin to tchl a when tchl $a$ was maximum at $T_{\text {peak }}$ ) during the summer experiment (Fig. 5b, Table 5). Overall, the change in tchl a observed in the single nutrient addition experiment amounted to $99 \%$ and $64 \%$ of the values measured in the winter and summer DSW experiments, respectively. The increase in CF rates stimulated by the addition of nitrate in the wintertime experiment was between $22 \%$ and $47 \%$ of the total and size-fractionated rates observed in the DSW addition experiments (Table 3). In contrast, the rate of whole community CF stimulated by the addition of nitrate in summertime experiments was $106 \pm 14 \%$ of that observed in the DSW addition experiments, with the contribution of the $0.2-2 \mu \mathrm{m}, 2-10 \mu \mathrm{m}$, and $>10 \mu \mathrm{m}$ size fractions being $160 \pm 14 \%, 88 \pm 36 \%$, and $87 \pm 23 \%$, respectively, of those observed in the DSW experiments (Table 4).

The concentration of fucoxanthin at $T_{\mathrm{f}}$ in the nitrate only enrichment experiments was 32 and $130 \%$ of that stimulated by the addition of DSW in winter and summer experiments, respectively. However, the contribution of fucoxanthin to tchl $a$ at $T_{\mathrm{f}}$ was higher in winter and summer experiments when DSW was added (13\% and $47 \%$, respectively) compared to when nitrate was added ( $7 \%$ and $35 \%$, respectively, Table 5). Note that the maximum concentrations of $\mathrm{chl} a$ and rates of $\mathrm{CF}$ were observed at different time points in the DSW and nitrate addition experiments (Figs. 3 \& 6).

\section{DISCUSSION}

The goal of this study was to investigate if the addition of nutrient-enriched DSW would stimulate a bloom of fast-growing, opportunistic phytoplankton in a water column that is permanently nutrient-depleted and typically dominated by cyanobacteria. Instead of observing a consistent and predictable bloom, we observed 2 distinct responses: a low yield and slow kinetic response in the fall and winter months, during which phototrophic biomass and CF rates increased to moderate bloom conditions, and a large yield and rapid kinetic response, during which there was a significant perturbation of the system, resulting in an accumulation of phototrophic biomass, a

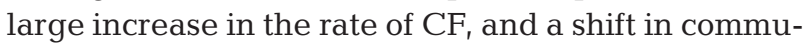
nity size and composition from PRO to SYN and diatoms. These results suggest a possible seasonal control in the response of the microbial ecosystem to nutrient perturbations and the probability of generating a significant accumulation of large phytoplankton in the oligotrophic NPSG, especially in summer. There are at least 4 possible explanations for these experimental observations: (1) seasonal changes in the supply of rate limiting nutrients; (2) seasonal changes in the seed population, specifically in the abundance of large cells; (3) seasonal variation in grazing; and (4) environmental controls such as light (light flux and day length) and temperature.

\section{Supply of rate limiting nutrients}

There was clear evidence for macronutrient limitation in all experiments, as phototrophic biomass and 

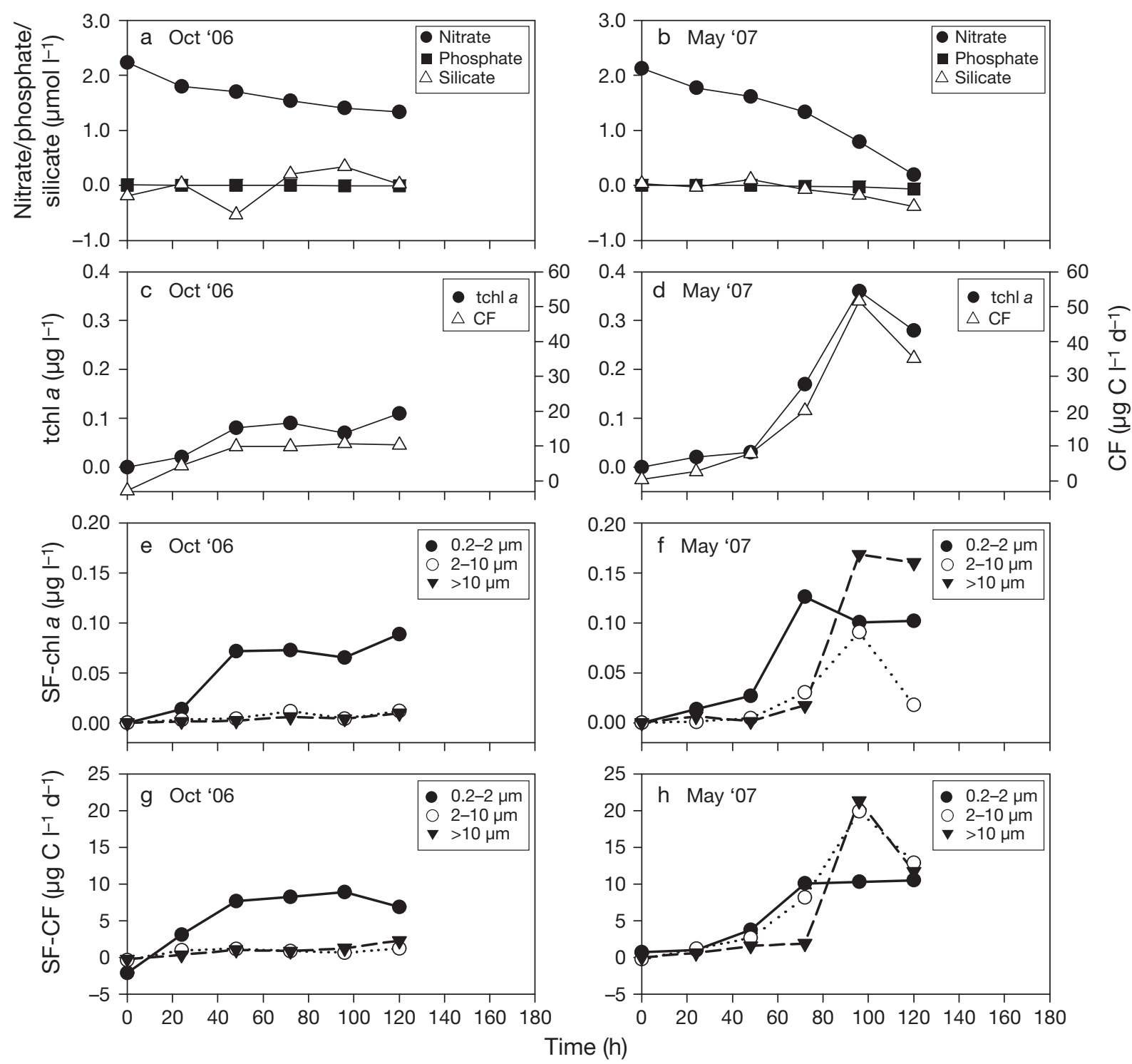

Fig. 6. Single nutrient (nitrate) addition experiment: nutrient concentration ( $\mu \mathrm{mol} \mathrm{l}^{-1}$ ), nitrate, phosphate, and silicate in (a)

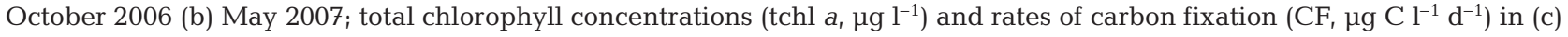
October 2006 and (d) May 2007; size-fractionated chlorophyll a (SF-chl $a, 0.2-2 \mu \mathrm{m}, 2-10 \mu \mathrm{m}$ and >10 $\mu \mathrm{m}$ ) in (e) October 2006 and (f) May 2007; size-fractionated CF rates (SF-CF, 0.2-2 $\mu \mathrm{m}, 2-10 \mu \mathrm{m}$ and >10 $\mu \mathrm{m}$ ) in (g) October 2006 and (h) May 2007.

Note that control incubation data has been subtracted from treatment incubation data for all parameters

CF rates were enhanced in all experiments, irrespective of season. Indeed, Station ALOHA is an oligotrophic ecosystem where less than $10 \%$ of the carbon that is fixed is exported from the euphotic zone; the remainder is remineralized (Karl et al. 1996). The typical concentration of nitrate $\left(2.6 \pm 3.2 \mathrm{nmol} \mathrm{l}^{-1}\right)$, phosphate $\left(51 \pm 30 \mathrm{nmol} \mathrm{l}^{-1}\right)$, and silicate $(1.2 \pm$ $\left.0.3 \mu \mathrm{mol} \mathrm{l^{-1 }}\right)$ in surface waters $(0-50 \mathrm{~m})$ would suggest that nitrate is the proximal limiting nutrient, as phosphate and silicate are in excess relative to the Redfield ratio (nitrate:phosphate $=0.05 \pm 0.11$, i.e. $<16: 1$; nitrate:silicate $=0.002 \pm 0.010$, i.e. $<1: 1$, relevant to diatom elemental stoichiometry; Redfield et al. 1963, Karl et al. 2001, Christian 2005). It is worth noting that we do not consider ammonium here, as it is typically less than $20 \mathrm{nM}$ at Station ALOHA, and therefore below the limits of detection of standard colorimetric techniques. On the other hand, the elemental stoichiometry of dissolved organic $\mathrm{N}$ to dissolved organic $\mathrm{P}$ (DON:DOP) is greater than 16:1, suggesting that the organic nutrient pool is a potential source of nitrogen. However, our lack of understanding of the chemical composition and bioavailability mean that its importance as a 
source of $\mathrm{N}$ remains uncertain, although strong vertical gradients in DON and DOP with depth imply that a significant proportion of the organic nutrient pools must be bioavailable. Furthermore, direct field studies show that nitrogen $\left(\mathrm{N}_{2}\right)$ fixation by diazotrophs partially relieves fixed nitrogen limitation at Station ALOHA, although the magnitude of nitrogen supplied may be constrained by phosphorus and/or iron (Dore et al. 2008, Church et al. 2009). Nevertheless, the biomass and rate of CF by the nondiazotrophic community is limited by nitrate (Christian 2005). This is clearly demonstrated by the single nutrient addition experiments performed in this study. We observed a seasonal response by phytoplankton to the addition of nitrate, which stimulated about half the microbial response observed in DSW incubations in the wintertime experiment but an equal or greater than response (when peak biomass and rates are compared) compared to DSW incubations in summertime experiments. This demonstrates the chronic nitrate limitation in this ecosystem yet the availability of other essential elements such as phosphate, silicate and iron, although significant seasonality in the availability of phosphate was observed. Similar nutrient addition experiments have been conducted in the oligotrophic northeast Atlantic Ocean (Mills et al. 2004) and Mediterranean Sea (Zohary et al. 2005). Mills et al. (2004) found that the simultaneous addition of nitrogen (nitrate plus ammonium), phosphate, and iron stimulated a 10fold increase in CF rate and chl within only $48 \mathrm{~h}$, whereas the addition of nitrate only stimulated a less than 3-fold increase in CF rate and chl, implying that a nutrient other than nitrate was limiting productivity in these waters. Zohary et al. (2005) compared the response of phytoplankton to ammonium plus phosphate and phosphate only in the eastern Mediterranean Sea, a region considered to be severely Plimited. Within $4 \mathrm{~d}$, there was a 9- to 16 -fold increase in concentrations of chl $a$, a 26 -fold increase in concentrations of fucoxanthin, and a 4 -fold increase in SYN abundance in response to the addition of ammonium plus phosphate, compared to a 2- to 3fold increase in chl a concentrations and a 4 -fold increase in fucoxanthin concentrations, with no change in SYN abundance in the phosphate only incubations (Zohary et al. 2005). They concluded that while bacteria may be limited by phosphorus, the entire phytoplankton community was co-limited by phosphorus and nitrogen. Similar to our observations, Zohary et al. (2005) also measured a decline in PRO by at least $50 \%$ in the phosphate only and phosphate plus ammonium experiments.
Time-series of near-surface mean $(0-35 \mathrm{~m}$, Fig. 1c,d) and integrated nutrients $(0-100 \mathrm{~m}$, data not shown) show that there are seasonal differences in nitrate between summer (June to August: $0.27 \pm$ $0.26 \mathrm{mmol}$ nitrate $\mathrm{m}^{-2}$ ) and winter (December to February: $1.88 \pm 3.33 \mathrm{mmol}$ nitrate $\mathrm{m}^{-2}$, Karl et al. 2001) at Station ALOHA, which are driven by physical processes, such as deepening of the winter mixed layer to a maximum of $130 \mathrm{~m}$, cyclonic eddy variability and eddy-wind interactions (Letelier et al. 2000). Note that nitrate concentrations are more variable in winter. Phosphate also varies seasonally but in contrast to nitrate, near-surface mean (Fig. 1d) and integrated concentrations of phosphate $(0-100 \mathrm{~m})$ are highest in spring and summer (5.4 to $5.5 \mathrm{mmol}$ phosphate $\mathrm{m}^{-2}$ ) and lowest in fall and winter (4.1 to $4.8 \mathrm{mmol}$ phosphate $\mathrm{m}^{-2}$ ), although the mechanisms driving seasonality in phosphate are not fully understood (Karl et al. 2001, Dore et al. 2008). Unlike phosphate, which tends to vary over annual timescales, pulses of nitrate are short-lived, highly variable between years (Karl et al. 2001), and may occur throughout the year. However, it is somewhat surprising that pulses of nitrate are observed at Station ALOHA. Firstly, the chance of sampling a pulse of nitrate during the $4 \mathrm{~d}$, near monthly HOT cruises to Station ALOHA is highly unlikely and perhaps provides insight into the potential frequency but undersampling of such events. Secondly, studies of the photo-physiology of phytoplankton communities at Station ALOHA reveal that the lowlight adapted communities living within the deep chlorophyll maximum are highly photosynthetically efficient with a large capacity to assimilate nitrate (Letelier et al. 2004, Corno et al. 2008). Finally, it is well know that SYN possess nitrate reductase, the gene that encodes for the utilization of nitrate, and recent evidence reveals that some strains of PRO also have the gene (Casey et al. 2007, Johnson \& Lin, 2009, Martiny et al. 2009) and therefore have the potential to up-regulate nitrate reductase in response to an injection of nutrients. Thus, with the predominance of cyanobacteria in surface waters at Station ALOHA with the ability to assimilate nitrate, as well as a background community of larger cells $(>2 \mu \mathrm{m})$ that are highly photosynthetically efficient (see discussion below on community structure, Li et al. 2011), we would expect the nutrient-impoverished phytoplankton community to assimilate nitrate injected into surface waters rapidly due to chronic nitrate limitation (but not phosphate limitation) and thus mask the signal of the physical pulse of nutrients. The fact that nitrate pulses are observed 
mostly in winter and spring, with fewer occurrences in summer and fall, means that there is uncoupling between the physical supply of nutrients and its assimilation by phytoplankton at Station ALOHA (Karl et al. 2001), thus providing evidence that the ecosystem is not poised to assimilate new nutrients in winter. This is in agreement with our experimental results, which show that nutrients were not readily assimilated in winter even by a nutrient-impoverished community. Thus, it is possible that phytoplankton community structure or another environmental condition plays a critical role in the ability of the ecosystem to respond to the addition of nutrients.

In this study, a single dose of nutrients (DSW or nitrate) was added to a set of 201 carboys and incubated on deck at a fixed light depth (see discussion below on light). However, there have been a number of attempts to study the impact of both artificial and natural fertilization of surface waters with nutrients. Kress et al. (2005) performed an in situ phosphorus addition experiment in the eastern Mediterranean in May 2002 as part of the CYCLOPS program, adding a single dose of phosphate to surface waters to gain a final in situ concentration of $110 \mathrm{nmol}^{-1}$. However, within $3 d, 75 \%$ of the added phosphorus was diluted by the surrounding low-phosphorus water, 15\% remained in the patch, and only $10 \%$ of the total phosphorus added was removed through biological uptake. Dilution of the added phosphorus below some threshold prevented phytoplankton from blooming. During a novel in situ experiment conducted in a low-chlorophyll region of the Philippine Sea in summer 2005, Maruyama et al. (2011) managed to maintain a continuous supply of nutrient-rich waters to the surface waters for $34 \mathrm{~d}$ using a $300 \mathrm{~m}$ pipe and pumping system. Chl a concentrations increased from $<0.05$ to $>1 \mu \mathrm{g} \mathrm{l}^{-1}$ within $10 \mathrm{~d}$ but increased up to $30 \mu \mathrm{g} \mathrm{l^{-1 }}$ after $20 \mathrm{~d}$. Although there were no data on species composition or CF rate (chl a was the only biological parameter monitored), the ability to sustain an input of nutrients clearly stimulated a biological response. Mesoscale eddies represent a natural nutrient addition mechanism. During a month-long study of a large, well-developed cyclonic mesoscale eddy generated to the south of the Hawaiian Islands, a 4-fold increase in nitrate, a 3-fold increase in carbon fixation, a 6-fold increase in fucoxanthin, and a 47-fold increase in diatom abundance were observed (Benitez-Nelson et al. 2007, Brown et al. 2008, Rii et al. 2008), with a 50\% decline in PRO cell abundance inside the eddy compared to the surrounding waters. Cyclonic eddies alter both the nutrient and light regime experienced by phytoplankton through uplift of isopycnals into the well-lit euphotic zone and thus multiple factors cause blooms to develop within eddies. However, the change in community composition reported within the eddy is similar to that observed in summertime experiments in this study, that is, a shift from small cyanobacteria to larger phytoplankton and a prevalence of diatoms. However, shipboard and in situ experiments and observations within eddies provide only a snapshot of the response of the microbial community to nutrient additions; yet as this study clearly shows, seasonality, as well as inter-annual variability in the response of the phototrophic community are potentially important factors for understanding ecosystem dynamics.

\section{Seasonality in community composition}

It is plausible that subtle variations in habitat conditions at Station ALOHA dictate the seasonally dependent magnitude of response and type of community that emerges after DSW additions. Small cells $(<2 \mu \mathrm{m})$ numerically dominate the microbial community in oligotrophic open ocean gyres due to their large surface area to volume ratio and thus their ability to outcompete larger cells for nutrients at low concentrations (Chisholm 1992, Li et al. 2011). Blooms of $<2 \mu \mathrm{m}$ phytoplankton cells, such as Synechococcus spp., do occur in the open ocean (Glover et al. 1988, 2007, McGillicuddy Jr. et al. 2007). Indeed, summertime SYN and PEUK abundance was more than double that observed throughout the rest of the year. The addition of DSW in May 2007 caused a 21-fold increase in the abundance of SYN cells (Table 5) and a significant increase in the chl $a$, rate of $\mathrm{CF}$ and growth rate of the $2-10 \mu \mathrm{m}$ size fraction (Table 4 , Fig. $4 i, j$ ). These observations demonstrate that there was a physiological response by the existing phytoplankton population rather than a shift in community structure with the addition of DSW. Interestingly, the addition of nitrate stimulated a similar magnitude of response as the DSW experiment.

Although there was enhanced abundance and contribution of PEUK and fucoxanthin to biomass and CF rate observed in May 2007, their contribution was more notable in the July 2006 experiment, when there was a 20-fold increase in PEUK cell abundance (Table 5) and a 17- (at $T_{\mathrm{f}}$ ) and 70-fold ( $\left.T_{\text {peak }}\right)$ increase in fucoxanthin concentrations, with fucoxanthin representing up to $71 \%$ of tchl a (Table 5, Fig. 5). Considering that the tchl a to fucoxanthin ratio for 
diatoms is 0.8 (Letelier et al. 1993), our results imply a significant increase in the contribution of diatoms to total cell abundance. Indeed, diatom abundance has been reported to be consistently low but persistent throughout the year at Station ALOHA (Scharek et al. 1999), both in the shallow waters and deep chlorophyll maximum (Venrick 1999). Venrick (1999) identified 3 layers of diatoms, dominated by Nitzschia and Mastogloia spp. in the surface layers and Pseudonitzschia spp. in the deeper waters ( 120 to $160 \mathrm{~m}$ ). Venrick (1993) postulates that the nutrient storage capacity of diatoms enables them to survive for prolonged periods in a low nutrient environment but that growth may be stimulated through mixing events which redistributes not only the diatoms but nutrients required for growth. A shift in the viability of diatoms from resting cysts to vegetative cells after the addition of nutrients has been observed during the North Atlantic bloom experiments (Rynearson et al. 2008). Stimulation of vegetative diatoms may explain our observations in summer experiments.

Despite their low abundance, chlorophyll normalized rates of $\mathrm{CF}$ for the $>2 \mu \mathrm{m}$ size fraction were found to be 2- to 9-fold higher than for the $0.2-2 \mu \mathrm{m}$ size fraction, implying that the $>2 \mu \mathrm{m}$ size fraction is more efficient at fixing carbon than the smaller cells (Li et al. 2011) and that this size class has the ability to grow rapidly under improved light and/or nutrient conditions. Therefore, a small change in the biomass of the $>2 \mu \mathrm{m}$ size fraction can have a large effect on the total rate of $\mathrm{CF}$ measured. However, this still leaves the question of why diatoms did not bloom in winter experiments. There are at least 2 explanations: either the abundance of diatoms (or rather, the $>2 \mu \mathrm{m}$ cells) was prohibitively low in winter months or the physiological status of diatoms meant that they were not 'primed' to grow rapidly in response to nutrient additions due to some other limiting factor. During the period of this study, integrated water column $(0-100 \mathrm{~m})$ concentrations of fucoxanthin and particulate silicate (PSi), crude indicators for diatom biomass, were higher in summertime (mean \pm standard deviation, $0.74 \pm 0.08 \mathrm{mg} \mathrm{m}^{-2}$ and $1.66 \pm 0.34$ mmol m${ }^{-2}$, respectively) compared to wintertime $\left(0.61 \pm 0.10 \mathrm{mg} \mathrm{m}^{-2}\right.$ and $1.35 \pm 0.45 \mathrm{mmol} \mathrm{m}^{-2}$, respectively) at Station ALOHA, but the difference was not statistically significant. Instead, the highest inventories of PSi (1.89 to $2.09 \mathrm{mmol} \mathrm{m}^{-2}$ ) were observed in July, September, and October 2004, and the lowest inventories ( 0.90 to $1.27 \mathrm{mmol} \mathrm{m}^{-2}$ ) were observed in May 2007, October 2005, and October 2006 (data not shown). Fucoxanthin concentrations were highest $\left(>0.73 \mathrm{mg} \mathrm{m}^{-2}\right)$ in October 2004, July
2006, and May 2007 and lowest $\left(<0.57 \mathrm{mg} \mathrm{m}^{-2}\right)$ in September and October 2004 and October 2006 (data not shown). Overall, it appears that diatom abundance was not significantly lower in winter than summer, and therefore seasonal differences in diatoms do not appear to explain the seasonal response of the microbial community to DSW additions. Alternatively, the physiological status of the phototrophic community at the start of the experiments may have differed between seasons. Indeed, there is evidence for frequent summertime diatom blooms in the NPSG (Brzezinski et al. 1998, Dore et al. 2008, Wilson \& Qiu 2008). Studies postulate that a combination of factors favor diatom growth in summer months, such as relatively high iron concentrations introduced by atmospheric deposition in late spring and early summer (Boyle et al. 2005), summertime shallow mixed layers, and high photon flux (Sunda \& Huntsman 1997, Scharek et al. 1999). These significant blooms are supported by $\mathrm{N}_{2}$ fixation at some stage throughout their lifetime, with diatoms being associated with endosymbiotic nitrogen fixers such as Richelia (Church et al. 2009), but their development during the summer months may be stunted by an insufficient supply of phosphate or iron (White et al. 2007, Dore et al. 2008). Addition of nutrient-enriched DSW to a surface phototrophic population 'primed' to bloom may have stimulated the dramatic increase in biomass and CF rate and enhanced the growth of large phytoplankton, as observed in the summertime experiments. Indeed, the abundance of SYN and PEUK in May 2007 was more than double that observed throughout the rest of the year. However, despite the PEUK abundance being 4 times higher in May compared to July 2006, PEUK abundance increased 20-fold in July, compared with 2- to 7-fold in May, during which a SYN bloom was observed. The reasons for increased abundance of SYN in May but PEUK in July is presently unknown.

One series of studies that has been able to rigorously address the impact of phytoplankton community structure on bloom formation is the iron addition experiments conducted in high nutrient, low chlorophyll (HNLC) regions of the ocean. A recent summary of data collected from 12 in situ iron addition experiments (Boyd et al. 2007) shows that the response of all species, from cyanobacteria to diatoms, can vary dramatically. They report that in HNLC regions, the interplay between factors, such as initial conditions and loss processes, determines the properties of the response such as bloom magnitude. They found that although all phytoplankton species initially responded to iron additions, only diatoms 
were able to bloom by increasing their growth rate relative to other phytoplankton species and thus escape grazing pressure (Boyd et al. 2007). Indeed, factors controlling bloom development in HNLC regions may be analogous to those found in the present study in the oligotrophic ocean.

\section{Grazing}

The growth rate potential of large phytoplankton ( $>2 \mu \mathrm{m}$, e.g. diatoms) and their high affinity for nutrients at high concentrations allows bloom development to occur despite their low initial cell abundance. Estimates of whole community and sizefractionated growth rates (Tables $3 \& 4$ ) show that algal growth in response to DSW addition was significantly higher in summer (mean $\pm \mathrm{SD} ; 0.45 \pm 0.08 \mathrm{~d}^{-1}$ at $T_{\mathrm{f}}$ and $0.6 \pm 0.1 \mathrm{~d}^{-1}$ at $\left.T_{\text {peak }}, \mathrm{p}<0.05\right)$ compared to winter $\left(0.2 \pm 0.1 \mathrm{~d}^{-1}\right)$ experiments. This seasonal difference is especially pronounced in the larger size fractions $(2-10 \mu \mathrm{m}$ and $>10 \mu \mathrm{m})$, demonstrating the opportunistic ability of larger cells to respond to pulses of nutrients and rapidly assimilate nutrients to near zero or below ambient concentrations, as observed in this study. For bloom development to occur, the growth rate of phytoplankton must be greater than the grazing and growth rate of zooplankton (Longhurst 1998, Cullen et al. 2002). Microzooplankton, which tend to feed on small cells, such as PRO (Caron et al. 1991) and may consume $>40 \%$ of chlorophyll and $>69 \%$ of primary production per day in the open ocean, exert a strong control over phytoplankton biomass in the open ocean (Calbet \& Landry 2004). Grazing by mesozooplankton, which tend to feed on larger cells ( $>2 \mu \mathrm{m}$; Isla et al. 2004) or protozoans, tends to be more dependent on ecosystem productivity (Calbet 2001), with a decline in ingestion rates as productivity decreases. At Station ALOHA, zooplankton abundance is greater during summer months compared to winter months (Landry et al. 2001, Sheridan \& Landry 2004). If there was top-down control of phototrophic biomass during the DSW addition experiments performed in this study, we would expect to see a greater enhancement of phototrophic biomass in winter rather than summer and this is not the case. Alternatively, if grazers or a specific size fraction of grazers (i.e. micro- or mesozooplankton) were excluded from the incubation bottles due to experiment setup and design, we would expect to see a greater increase in phototrophic biomass in the control incubations, or a change in a specific species of a size fraction, depending on the size of grazer excluded. However, there was no consistent or significant increase in phototrophic biomass in control incubations, and we observed enhanced growth rates of both the $2-10 \mu \mathrm{m}$ size fraction (May 2007 ) and the $>10 \mu \mathrm{m}$ size fraction (July 2006). Thus, we believe that grazing by zooplankton did not exert a strong control over the seasonal response of the phototrophic community to the addition of DSW.

\section{Environmental controls}

Photoperiodism in higher plants has long been attributed to phytochrome response to red and far red light and is known to regulate growth patterns, such as the onset of flowering and germination of seeds (Salisbury \& Ross 1985). More recently, gene sequences for phytochromes, as well as cryptochromes, which absorb light in the blue spectrum, have been discovered in marine phytoplankton, including diatoms (Leblanc et al. 1999, Montsant et al. 2007). Although the precise actions of these pigments in marine diatoms are not well understood, it is likely that they do inform on circadian rhythms and, hence, may be important in signaling day length or rate changes in day length. If the day length, or rate of change, is important in the regulation of diatom growth rates in the NPSG, then our results may be indicative of this light control, possibly via phytochrome/cryptochrome signaling. If diatom growth rate response is relying more on light periodicity than on ambient nutrient concentrations, and the light cue is missing, then the growth response of diatoms will be low even in the presence of a sufficient nutrient supply, as observed here in the winter experiments. However, during periods of the year when light cues are present, the response to nutrients will be high exponential growth rates, such as those observed for the summertime experiments in the $>10 \mu \mathrm{m}$ size fraction. Indeed, we found a significant positive relationship between light flux (Table 1) and $\mu$ for the total phytoplankton community (Table $3, \mathrm{p}=0.014, \mathrm{R}^{2}=$ $0.553, \mathrm{n}=10$ ). Further examination of the size fractions revealed that the relationship was strong for the $2-10 \mu \mathrm{m}$ and $>10 \mu \mathrm{m}$ size fractions specifically, although the relationship was only significant for the 2-10 $\mu \mathrm{m}$ size fraction using growth calculated to $T_{\text {peak }}\left(p=0.018, R^{2}=0.88\right)$. Indeed, Li et al. (2011) found that the irradiance required to saturate in situ productivity was lower for the $0.2-2 \mu \mathrm{m}$ size fraction compared to the $>2 \mu \mathrm{m}$ size fraction, implying reduced growth of the $>2 \mu \mathrm{m}$ size fractions in relatively low light periods, e.g. winter. Thus, the sea- 
sonal pattern in the average light flux during our experimental incubations at Station ALOHA, with significantly lower light flux in winter $\left(31 \pm 6 \mathrm{E} \mathrm{m}^{-2}\right.$ $\left.\mathrm{d}^{-1}\right)$ compared to summer $\left(48 \pm 3 \mathrm{E} \mathrm{m}^{-2} \mathrm{~d}^{-1}\right.$, Table 1$)$, may to some degree explain the seasonal response of phytoplankton and large size fractions $(>2 \mu \mathrm{m})$ to the addition of nutrients. This seasonal change in light conditions is also reflected in a deepening of the $1 \%$ sea-surface photosynthetically active radiation (PAR) depth (euphotic zone) from $105 \mathrm{~m}$ in winter to $121 \mathrm{~m}$ in summer (Letelier et al. 2004), as well as an increase in day length of approximately $2 \mathrm{~h}$ from wintertime to summertime incubations (Table 1). Furthermore, Smith \& Eppley (1982) found that variation in day length between $10.1 \mathrm{~h}$ and $14.3 \mathrm{~h}$ accounted for $23 \pm 9 \%$ (mean $\pm 1 \mathrm{SD}$ ) of the variability in rates of primary production determined in the Southern California Bight, although the relationship between primary production and day length appeared to be non-linear. More recently, Li et al. (2011) reported that variation in downwelling light field explained $>50 \%$ of the variability associated with primary production and chlorophyll normalized primary production for the $0.2-2 \mu \mathrm{m}$ (52 to $57 \%$ ) and $>2 \mu \mathrm{m}$ (55 to $67 \%$ ) size fractions at Station ALOHA.

The irradiance received by a phytoplankton cell is also a function of the MLD, rate of mixing, and attenuation of light through the water column. At Station ALOHA, the MLD is typically shallower in summer (mean $\pm \mathrm{SD}, 46 \pm 3 \mathrm{~m}, \mathrm{n}=53$ ) and significantly deeper and more variable in winter months $(83 \pm 13 \mathrm{~m}, \mathrm{n}=$ 56, Fig. 1b). It is conceivable that the seasonal response observed during the incubation experiments was simply due to the change in incident irradiance received by phytoplankton during incubation at a fixed light depth of $30 \mathrm{~m}$, compared to the variable irradiance experienced in the water column ( $\mathrm{Li}$ et al. 2011). The effect of a changed light field would have been experienced by phytoplankton in both the control and treatment incubations, and therefore the impact of an increase or reduction of light (e.g. on chl a or $\mathrm{CF}$ rate) was taken into account by control correcting data from the treatment incubations.

\section{CONCLUSIONS AND BROADER IMPLICATIONS}

In this study, we observed a seasonal response by phytoplankton to the addition of nutrient-enriched DSW, with chl a concentrations and CF rates being significantly higher in summer compared to winter by the end of the experiments (up to $170 \mathrm{~h}$ ). A shift in community size structure from small phytoplankton
$(0.2-2 \mu \mathrm{m})$ to large phytoplankton $(>2 \mu \mathrm{m})$ was observed in summer but not in winter, with summertime blooms being dominated by SYN or diatoms. Indeed nutrient pulses are observed at Station ALOHA during winter and spring, implying that the wintertime phytoplankton population is not 'poised' to assimilate nitrate, despite having the ability to do so. Thus, the reason for the winter population being unable to draw down nutrients rapidly is presently unknown. Grazer abundance is seasonal at Station ALOHA but is higher in summer relative to winter and so does not explain why phytoplankton are able to bloom in summer but not in winter. Seasonal changes in community structure appear to be rather subtle using methods applied in this study, and thus more targeted techniques may be required (e.g. microscopy, molecular techniques) to detect the rarer, larger cells in order to examine how phytoplankton community structure varies with time. Finally, the one environmental factor that changes in a predictable or regular manner is light. Recent studies at Station ALOHA (Li et al. 2011, Karl et al. 2012) highlight the importance of the variation in irradiance through the water column, change in day length and the sun's angle in controlling the growth of specific phytoplankton size classes and the demise of surface blooms. Clearly, further investigation into phytoplankton community structure, photo-physiology, and changes in the light field is required to fully understand why phytoplankton respond seasonally to nutrient additions in the tropical oceans, where the variability in seasonal parameters is low.

Due to their areal expanse, subtropical regions are responsible for 50 to $80 \%$ of oceanic organic carbon export (Martin et al. 1987, Karl et al. 1996, Emerson et al. 1997). Our knowledge of community development during blooms in these important regions remains poor. The seasonal dependence of bloom formation found in this study has implications for events that may stimulate production, such as mesoscale eddies and Rossby waves. Passage of such mesoscale, and perhaps sub-mesoscale, physical structures may only stimulate production and carbon drawdown through sinking of particulate matter in the summer months, when the system is primed to support a bloom. Throughout the rest of the year, the impact of mesoscale features may be relatively small. In addition, it is probable that the response of the phototrophic community to artificial fertilization of the upper oligotrophic ocean, to increase fisheries yields (Maruyama et al. 2011), sequester carbon (Lovelock \& Rapley 2007, Karl \& Letelier 2008, White et al. 2010) or as discharge from ocean thermal 
energy conversion (OTEC) facilities, will vary in magnitude, and carbon drawdown potential. Instead, the response of the phototrophic community will be highly dependent on the pre-existing physical, possibly seasonal, and biological conditions at the time of nutrient introduction.

Acknowledgements. The authors thank the Hawaii Ocean Time-series (HOT) personnel, the Captain, crew and technical support of the RV 'Kilo Moana' and RV 'Ka'imikai-OKanaloa'. We thank R. Bidigare for HPLC analysis, K. Doggett for help with flow cytometry and S. Reynolds for help with graphics. We acknowledge 5 anonymous reviewers and P. Boyd and R. Letelier for their constructive comments that helped to improve this manuscript. This work was supported by NSF (OCE-0326616 and EF-04245999) and Gordon and Betty Moore Foundation Marine Microbiology Initiative.

\section{LITERATURE CITED}

Armstrong FAJ, Sterns CR, Strickland JDH (1967) The measurements of upwelling and subsequent biological processes by means of a Technicon Autoanalyzer ${ }^{\circledR}$ and associated equipment. Deep-Sea Res 14:381-389

> Barber RT, Hiscock MR (2006) A rising tide lifts all phytoplankton: growth response of other phytoplankton taxa in diatom-dominated blooms. Global Biogeochem Cycles 20:GB4S03 doi:10.1029/2006GB002726

Benitez-Nelson CR, Bidigare RR, Dickey R, Landry MR and others (2007) Mesoscale eddies drive increased silica export in the subtropical Pacific Ocean. Science 316: 1017-1021

- Bingham FM, Lukas R (1996) Seasonal cycles of temperature, salinity and dissolved oxygen observed in the Hawaii Ocean Time-series. Deep-Sea Res II 43:199-213

Boyd PW, Jickells T, Law CS, Blain S and others (2007) Mesoscale iron enrichment experiments 1993-2005: synthesis and future directions. Science 315:612-617

Boyd PW, Gall MP, Silver MW, Coale SL, Bidigare RR, Bishop JLKB (2008) Quantifying the surface-subsurface biogeochemical coupling during the VERTIGO ALOHA and K2 studies. Deep-Sea Res II 55:1578-1593

Boyle EA, Bergquist BA, Kayser RA (2005) Iron, manganese, and lead at Hawaii Ocean Time-series Station ALOHA: temporal variability and intermediate water hydrothermal plume. Geochim Cosmochim Acta 69:933-952

> Brown SL, Landry MR, Selph KE, Yang EJ, Rii YM, Bidigare RR (2008) Diatoms in the desert: plankton community response to a mesoscale eddy in the subtropical North Pacific. Deep-Sea Res II 55:1321-1333

> Brzezinski MA, Villareal TA, Lipschultz F (1998) Silica production and the contribution of diatoms to new and primary production in the central North Pacific. Mar Ecol Prog Ser 167:89-104

Calbet A (2001) Mesozooplankton grazing effect on primary production: a global comparative analysis in marine ecosystems. Limnol Oceanogr 46:1824-1830

> Calbet A, Landry M (2004) Phytoplankton growth, microzooplankton grazing, and carbon cycling in marine systems. Limnol Oceanogr 49:51-57

Calil PHR, Doney SC, Yumimoto K, Eguchi K, Takemura T (2011) Episodic upwelling and dust deposition as bloom triggers in low nutrient, low chlorophyll regions. J Geophys Res 116 doi:10.1029/2010JC006704

Caron DA, Lim EL, Miceli G, Waterbury JB, Valois FW (1991) Grazing and utilization of chroococcoid cyanobacteria and heterotrophic bacteria by protozoa in laboratory cultures and a coastal plankton community. Mar Ecol Prog Ser 76:205-217

- Casey JR, Lomas MW, Mandecki J, Walker DE (2007) Prochlorococcus contributes to new production in the Sargasso Sea deep chlorophyll maximum. Geophys Res Lett 34:L10604 doi:10.1029/2006GL028725

Chisholm SW (1992) Phytoplankton size. In: Falkowski PG, Woodhead AD (eds) Primary productivity and biogeochemical cycles in the sea. Plenum Press, New York, NY, p 213-217

Christian JR (2005) Biogeochemical cycling in the oligotrophic ocean: Redfield and non-Redfield models. Limnol Oceanogr 50:646-657

Church MJ, Mahaffey C, Letelier RM, Lukas R, Zehr JP, Karl DM (2009) Physical forcing of nitrogen fixation and diazotrophic community structure in the North Pacific subtropical gyre. Global Biogeochem Cycles 23:GB2020 doi:10.1029/2008GB003418

Claustre H (1994) The trophic status of various oceanic provinces revealed by phytoplankton pigment signatures. Limnol Oceanogr 39:1206-1210

> Corno G, Letelier RM, Abbott MR (2008) Temporal and vertical variability in photosynthesis in the North Pacific Subtropical Gyre. Limnol Oceanogr 53:1252-1265

Cullen JJ, Franks PJS, Karl DM, Longhurst A (2002). Physical influences on marine ecosystem dynamics. In: Robinson AR, McCarthy JJ, Rothschild BJ (eds) The sea, Vol 12. John Wiley \& Sons, New York, NY, p 297-336

> Decembrini F, Caroppo C, Azzaro M (2009) Size structure and production of phytoplankton community and carbon pathways channeling in the Southern Tyrrhenian Sea (Western Mediterranean). Deep-Sea Res II 56:687-699

> Dore JE, Karl DM (1996) Nitrite distributions and dynamics at Station ALOHA. Deep-Sea Res II 43:385-402

> Dore JE, Letelier RM, Church MJ, Lukas R, Karl DM (2008) Summer phytoplankton blooms in the oligotrophic North Pacific subtropical gyre: historical perspective and recent observations. Prog Oceanogr 76:2-38

Emerson S, Quay P, Karl D, Winn C, Tupas L, Landry M (1997) Experimental determination of the organic carbon flux from open-ocean surface waters. Nature 389: 951-954

> Emerson S, Stump C, Johnson B, Karl DM (2002) In situ determination of oxygen and nitrogen dynamics in the upper ocean. Deep-Sea Res I 49:941-952

Eppley RW, Peterson BJ (1979) Particulate organic matter flux and planktonic new production in the deep ocean. Nature 282:677-680

Fogg GE, Thake B (1987) Algal cultures and phytoplankton ecology, 3rd edn. University of Wisconsin Press, Madison, WI

> Fong AA, Karl DM, Lukas R, Letelier RM, Zehr JP, Church MJ (2008) Nitrogen fixation in an anticyclonic eddy in the oligotrophic North Pacific Ocean. ISME J 2:663-676

> Garside C (1982) A chemiluminescent technique for the determination of nanomolar concentrations of nitrate and nitrite in seawater. Mar Chem 11:159-167

> Glover HE, Prezelin BB, Campbell L, Wyman M, Garside C (1988) A nitrate-dependent Synechococcus bloom in the surface Sargasso Sea water. Nature 331:161-163 
Glover HE, Garside C, Trees CC (2007) Physiological responses of Sargasso Sea picoplankton to nanomolar nitrate perturbations. J Plankton Res 29:263-274

Isla JA, Llope M, Anadón R (2004) Size-fractionated mesozooplankton biomass, metabolism and grazing along a $50^{\circ} \mathrm{N}-30^{\circ} \mathrm{S}$ transect of the Atlantic Ocean. J Plankton Res 26:1301-1313

> Johnson ZI, Lin Y (2009) Prochlorococcus: approved for export. Proc Natl Acad Sci USA 106:10400-10401

> Johnson KS, Riser SC, Karl DM (2010) Nitrate supply from deep to near-surface waters of the North Pacific subtropical gyre. Nature 465:1062-1065

> Karl DM (1999) A sea of change: biogeochemical variability in the North Pacific Subtropical Gyre. Ecosystems 2: 181-214

Karl DM, Letelier RM (2008) Nitrogen fixation-enhanced carbon sequestration in low nitrate, low chlorophyll seascapes. Mar Ecol Prog Ser 364:257-268

Karl DM, Tien G (1992) MAGIC: a sensitive and precise method for measuring dissolved phosphorus in aquatic environments. Limnol Oceanogr 37:105-116

Karl DM, Letelier R, Hebel D, Tupas L, Dore J, Christian J, Winn C (1995) Ecosystem changes in the North Pacific subtropical gyre attributed to the 1991-92 El Niño. Nature 373:230-234

Karl DM, Christian JR, Dore JE, Hebel DV, Letelier RM, Tupas LM, Winn CD (1996) Seasonal and interannual variability in primary production and particle flux at Station ALOHA. Deep-Sea Res II 43:539-568

Karl DM, Bidigare RR, Letelier RM (2001) Long-term changes in plankton community structure and productivity in the North Pacific Subtropical Gyre: the domain shift hypothesis. Deep-Sea Res II 48:1449-1470

Karl DM, Church MJ, Dore JE, Letelier RM, Mahaffey C (2012) Predictable and efficient carbon sequestration in the North Pacific Ocean supported by symbiotic nitrogen fixation. Proc Natl Acad Sci USA 109:1842-1849

- Kress N, Thingstad TF, Pitta P, Psarra S and others (2005) Effect of $\mathrm{P}$ and $\mathrm{N}$ addition to oligotrophic eastern Mediterranean waters influenced by near-shore waters. A microcosm experiment. Deep-Sea Res II 52:3054-3073

> Landry MR, Kirchman DL (2002) Microbial community structure and variability in the tropical Pacific. Deep-Sea Res II 49:2669-2693

> Landry MR, Al-Mutairi H, Selph KE, Christensen S, Nunnery S (2001) Seasonal patterns of mesozooplankton abundance and biomass at Station ALOHA. Deep-Sea Res II 48:2037-2062

Leblanc C, Falciatore A, Watanabe M, Bowler C (1999) Semi-quantitative RT-PCR analysis of photoregulated gene expression in marine diatoms. Plant Mol Biol 40: 1031-1044

Letelier RM, Bidigare RR, Hebel DV, Ondrusek M, Winn CD, Karl DM (1993) Temporal variability of phytoplankton community structure based on pigment analysis. Limnol Oceanogr 38:1420-1437

Letelier RM, Karl DM, Abbott MR, Flament P, Freiclich M, Lukas R, Strub T (2000) The role of late winter mesoscale events in the biogeochemical variability of the upper water column of the North Pacific Subtropical Gyre. J Geophys Res 105:28, 723-728, 739

Letelier RM, Karl DM, Abbott MR, Bidigare RR (2004) Light driven seasonal patterns of chlorophyll and nitrate in the lower euphotic zone of the North Pacific Subtropical Gyre. Limnol Oceanogr 49:508-519
Li B, Karl DM, Letelier RM, Church MJ (2011) Size-dependent photosynthetic variability in the North Pacific Subtropical Gyre. Mar Ecol Prog Ser 440:27-40

> Lomas ML, Moran SB (2011) Evidence for aggregation and export of cyanobacteria and nano-eukaryotes from the Sargasso Sea euphotic zone. Biogeosciences 8:203-216

Longhurst A (1998) Ecological geography of the sea. Academic Press, San Diego, CA

Lovelock JE, Rapley CG (2007) Ocean pipes could help the Earth to cure itself. Nature 449:403

Martin JH, Knauer GA, Karl DM, Broenkow WW (1987) VERTEX: carbon cycling in the northeast Pacific. DeepSea Res 34:267-285.

Martiny AC, Kathuria S, Berube PM (2009) Widespread metabolic potential for nitrite and nitrate assimilation among Prochlorococcus ecotypes. Proc Natl Acad Sci USA 106:10787-10792

> Maruyama S, Yabuki T, Sato T, Tsubaki K and others (2011) Evidences of increasing primary production in the ocean by Stommel's perpetual salt fountain. Deep-Sea Res I 58:567-574

- McAndrew PM, Björkman KM, Church MJ, Morris PJ, Jachowski N, Williams PJ leB, Karl DM (2007) Metabolic response of oligotrophic plankton communities to deep water nutrient enrichment. Mar Ecol Prog Ser 332:63-75

McGillicuddy Jr. DJ, Anderson LA, Bates NR, Bibby T and others (2007) Eddy/wind interactions stimulate extraordinary mid-ocean plankton blooms. Science 316: 1021-1026

Mills MM, Ridame C, Davey M, La Roche J, Geider RJ (2004) Iron and phosphorus co-limit nitrogen fixation in the eastern tropical North Atlantic. Nature 429:292-294

> Montsant A, Allen AE, Coesel S, De Martino A and others (2007) Identification and comparative genomic analysis of signaling and regulatory components in the diatom Thalassiosira pseudonana. J Phycol 43:585-604

> Murphy J, Riley JP (1962) A modified single solution method for the determination of phosphate in natural waters. Anal Chim Acta 27:31-36

Redfield AC, Ketchum BH, Richards FA (1963) The influence of organisms on the composition of seawater. In: Hill MN (ed) The sea, Vol 2. John Wiley \& Sons, New York, NY p 26-77

Richardson TL, Jackson GA (2007) Small phytoplankton and carbon export from the surface ocean. Science 315: 838-840

Rii YM, Brown SL, Nencioli F, Kuwahara V, Dickey T, Karl DM, Bidigare RR (2008) The transient oasis: nutrientphytoplankton dynamics and particle export in Hawaiian lee cyclones. Deep-Sea Res II 55:1275-1290

Rynearson R, Lampitt R, Poulton N, Richardson K, Sieracki M, Perry M (2008) Return from the depths: examination of diatom resting cysts from the North Atlantic Bloom Experiment. American Geophysical Union, Fall meeting. Abstract no. OS31A-1254. AGU, San Francisco, CA

> Sakamoto CM, Karl DM, Jannasch HW, Bidigare RR and others (2004) Influence of Rossby waves on nutrient dynamics and the plankton community structure in the North Pacific Subtropical Gyre. J Geophys Res 109 doi:10.1029/2003JC001976

Salisbury FB, Ross CW (1985) Plant physiology, 3rd edn. Wadsworth, Belmont, CA

Sarthou G, Timmermans KR, Blain S, Tréguer P (2005) Growth physiology and fate of diatoms in the ocean: a review. J Sea Res 53:25-42 
Scharek R, Latasa M, Karl DM, Bidigare RR (1999) Temporal variations in diatom abundance and downward vertical flux in the oligotrophic North Pacific gyre. Deep-Sea Res I 46:1051-1075

Sheridan CC, Landry MR (2004) A 9-year increasing trend in mesozooplankton biomass at the Hawaii Ocean Timeseries Station ALOHA. ICES J Mar Sci 61:457-463

Smith PE, Eppley RW (1982) Primary production and the anchovy population in the Southern California Bight: comparison of the time series. Limnol Oceanogr 27: $1-17$

Strickland JDH, Parsons TR (1972) A practical handbook of seawater analysis, 2nd edn. Bull Fish Res Board Can 167

Subramaniam A, Yager PL, Carpenter EJ, Mahaffey C and others (2008) Amazon River enhances diazotrophy and carbon sequestration in the tropical North Atlantic Ocean. Proc Natl Acad Sci USA 105:10460-10465

Sunda WG, Huntsman SA (1997) Interrelated influence of iron, light and cell-size on marine phytoplankton growth. Nature 390:389-392

Venrick EL (1993) Phytoplankton seasonality in the central North Pacific: the endless summer reconsidered. Limnol Oceanogr 38:1135-1149

Venrick EL (1999) Phytoplankton species structure in the central North Pacific, 1973-1996: variability and persistence. J Plankton Res 21:1029-1042

Editorial responsibility: Katherine Richardson, Copenhagen, Denmark
Welschmeyer NA (1994) Fluorometric analysis of chlorophyll $a$ in the presence of chlorophyll $b$ and pheopigments. Limnol Oceanogr 39:1985-1992

> White AE, Spitz YH, Letelier RM (2007) What factors are driving summer phytoplankton blooms in the North Pacific subtropical gyre? J Geophys Res 112:C12006

> White AE, Björkman K, Grabowski E, Letelier R, Poulos S, Watkins B, Karl D (2010) An open ocean trial of controlled upwelling using wave pump technology. J Atmos Ocean Technol 27:385-396

Wilson C, Qiu X (2008) Global distribution of summer chlorophyll blooms in the oligotrophic gyres. Prog Oceanogr 78:107-134

Wilson C, Villareal TA, Maximenko N, Bograd SJ, Montoya JP, Schoenbaechler CA (2007) Biological and physical forcings of late summer chlorophyll blooms at $30^{\circ} \mathrm{N}$ in the oligotrophic Pacific. J Mar Syst 64:164-176

Wright SW, Jeffrey SW, Mantoura RFC, Llewellyn CA, Bjornland T, Repeta D, Welschmeyer N (1991) Improved HPLC method for the analysis of chlorophylls and carotenoids from marine phytoplankton. Mar Ecol Prog Ser 77:183-196

> Zohary T, Herut B, Krom MD, Mantoura RFC and others (2005) P-limited bacteria but N and P co-limited phytoplankton in the Eastern Mediterranean-a microcosm experiment. Deep-Sea Res II 52:3011-3023

Submitted: July 4, 2011; Accepted: March 3, 2012

Proofs received from author(s): July 12, 2012 